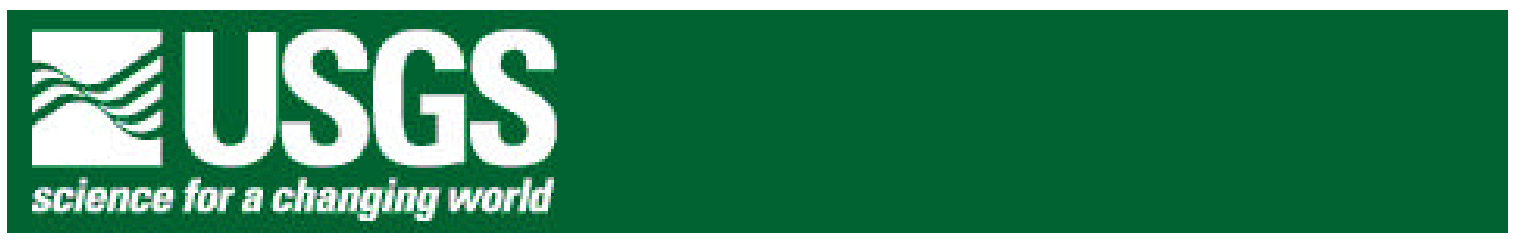

\title{
Seismic Images and Fault Relations of the Santa Monica Thrust Fault, West Los Angeles, California
}

\author{
by R. D. Catchings 1 , G. Gandhok ${ }^{1}$, M. R. Goldman ${ }^{1}$, and D. Okaya ${ }^{2}$ \\ Open-File Report 01-111
}

2001

This report is preliminary and has not been reviewed for conformity with U.S. Geological Survey editorial standards or with the North American Stratigraphic Code. Any use of trade, firm, or product names is for descriptive purposes only and does not imply endorsement by the U.S. Government.

\section{U.S. DEPARTMENT OF THE INTERIOR}

U.S. GEOLOGICAL SURVEY

${ }^{1}$ U.S. Geological Survey, 345 Middlefield Rd, MS 977, Menlo Park, CA 94025

${ }^{2}$ Univ. of Southern California, Dept. of Geological Sciences, Los Angeles, CA 90089 


\section{Introduction}

In May 1997, the US Geological Survey (USGS) and the University of Southern California (USC) acquired high-resolution seismic reflection and refraction images on the grounds of the Wadsworth Veterans Administration Hospital (WVAH) in the city of Los Angeles (Fig. 1a,b). The objective of the seismic survey was to better understand the near-surface geometry and faulting characteristics of the Santa Monica fault zone. In this report, we present seismic images, an interpretation of those images, and a comparison of our results with results from studies by Dolan and Pratt (1997), Pratt et al. (1998) and Gibbs et al. (2000).

The Santa Monica fault is one of the several northeast-southwest-trending, north-dipping, reverse faults that extend through the Los Angeles metropolitan area (Fig. 1a). Through much of area, the Santa Monica fault trends subparallel to the Hollywood fault, but the two faults apparently join into a single fault zone to the southwest and to the northeast (Dolan et al., 1995). The Santa Monica and Hollywood faults may be part of a larger fault system that extends from the Pacific Ocean to the Transverse Ranges. Crook et al. (1983) refer to this fault system as the Malibu Coast-Santa Monica-Raymond-Cucamonga fault system. They suggest that these faults have not formed a contiguous zone since the Pleistocene and conclude that each of the faults should be treated as a separate fault with respect to seismic hazards. However, Dolan et al. (1995) suggest that the Hollywood and Santa Monica faults are capable of generating Mw 6.8 and Mw 7.0 earthquakes, respectively. Thus, regardless of whether the overall fault system is connected and capable of rupturing in one event, individually, each of the faults present a sizable earthquake hazard to the Los Angeles metropolitan area. If, however, these faults are connected, and they were to rupture along a continuous fault rupture, the resulting hazard would be even greater.

Although the Santa Monica fault represents a hazard to millions of people, its lateral extent and rupture history are not well known, due largely to limited knowledge of the fault location, geometry, and relationship to other faults. The Santa Monica fault has been obscured at the surface by alluvium and urbanization. For example, Dolan et al. (1995) could find only one 200-m-long stretch of the Santa Monica fault that was not covered by either streets or buildings. Of the 19-km length onshore section of the Santa Monica fault, its apparent location has been delineated largely on the basis of geomorphic features and oil-well drilling. Seismic imaging efforts, in combination with other investigative methods, may be the best approach in locating and understanding the Santa Monica fault in the Los Angeles region.

This investigation and another recent seismic imaging investigation (Pratt et al., 1998) were undertaken to resolve the near-surface location, fault geometry, and faulting relations associated with the Santa Monica fault.

\section{Local Geology and Tectonics}

The study area lies within the Los Angeles basin, which is bounded on the west by the Pacific Ocean and on the north by the Santa Monica mountains. The Santa Monica mountains are the southernmost ranges of the Transverse Ranges, an east-west belt of mountain ranges extending across much of southern 
California, including the area immediately north of the Los Angeles Basin. The northernmost Los Angeles basin consist of crystalline basement rocks that are unconformably overlain by a thick section of complexly folded and faulted middle Miocene to upper Pliocene petroliferous marine sandstones and shales (Hill et al., 1979). The Tertiary rocks are unconformably overlain by Pleistocene fresh-water bearing, largely continental sands, gravels, and shales, which are covered locally by Holocene alluvium (Hill et al., 1979).

The entire sequence of sediments and basement rocks are cut and bound by a complex pattern of faults. These faults include a wide range of fault types, including those with components of reverse, strike-slip, and normal faulting. The Santa Monica and Hollywood faults are two of a series of east-southeasttrending faults that extend more than $200 \mathrm{~km}$ across southern California and accommodate westward motion of the Transverse Ranges (Dolan et al., 1997). The Hollywood fault is a left-lateral, oblique-reverse fault that separates the Los Angeles basin and the Santa Monica mountains. The Santa Monica fault, located south of the Hollywood fault, is probably connected to the Hollywood and other faults at depth and laterally to the east and west of the Los Angeles basin (Davis and Namson, 1994). Ziony and Yerkes (1985) suggest that the Santa Monica fault is Late Quaternary in age, has a strike of about $\mathrm{N} 60-80^{\circ} \mathrm{E}$, and is presumed to dip $45-65^{\circ} \mathrm{NW}$ at depth, with some vertical near-surface traces. The Santa Monica fault is a reverse left-oblique-dip fault, and its surface expression includes offset stratigraphy, fault-produced physiographic features, and groundwater impediments within the Late Quaternary alluvial deposits (Hill et al., 1979). Clark et al. (1984) suggest that the vertical-component of the slip rate along the fault ranges from 0.27-0.39 mm/yr., and Dolan and Pratt (1997) suggest a dip-slip rate of $\sim 0.5 \mathrm{~mm} / \mathrm{yr}$. The Santa Monica fault offsets late Pleistocene deposits eastward to its intersection with the northwest-trending Newport -Inglewood fault zone but further east, late Quaternary deposits apparently are undisturbed by the presence of the Santa Monica fault (Ziony and Jones, 1989).

The Santa Monica fault consists of one or more strands and is about $40 \mathrm{~km}$ long. It has been delineated locally at depths of several thousand feet through exploratory oil well drilling and oil field development (Hill et al., 1979). Pleistocene or Holocene movement is evident locally along some fault segments in the zone, but the recurrence interval and recency of movement along many fault segments are not well documented, mainly because intense urbanization has modified or destroyed any surface traces of the fault (Hill et al., 1979).

In addition to the east-southeast-trending faults, many known faults within the Los Angeles basin have a predominant northwest-southeast strike. The northwest-trending faults and folds are overridden by or merge with the east-trending Santa Monica reverse fault (Yerkes and Lee, 1979). Several of the major northwest-trending faults in the area include the Charmocke, the Overland Avenue, and the Newport-Inglewood faults (Fig. 1a). These faults have largely strike-slip motion, but some sub-parallel faults in the Los Angeles Basin have thrust or reverse motion, including the Elysian Park and Compton thrust faults. 


\section{Seismic Survey}

In April 1997, an approximately 158-m-long seismic reflection/refraction survey was conducted by the US Geological Survey-Menlo Park, HighResolution Seismic Imaging Group (SIG) on the grounds of the WVAH in the city of Los Angeles (Fig. 1b). In this report, we refer to this seismic profile as the WVAH profile. For the WVAH profile, approximately $2 \mathrm{~s}$ of data were recorded on a Geometrics Strataview RX ${ }^{\mathrm{TM}}$ seismograph with 60 active channels. The data were stored on the hard drive of the Geometrics Strataview computer during field acquisition and were later downloaded to 4-mm tape for permanent storage in SEG-Y format.

Sensors consisted of $6040-\mathrm{Hz}$, single-element, Mark Products L-40A ${ }^{\mathrm{TM}}$ geophones spaced at 2-m increments along the profile. Seismic sources (shots), located at a depth of about $0.4 \mathrm{~m}$, were generated by a BETSY Seisgun ${ }^{\mathrm{TM}}$ using 8gauge shotgun blanks. Shots were spaced at 2-m increments along the profile and were co-located (1-m lateral offset) with the geophones. Shot timing was determined electronically at the seismic source when a hammer, used to trigger the seisgun, electrically closed contact with the Betsy Seisgun, sending an electrical signal to the seismograph.

Table 1. Acquisition parameters for Santa Monica seismic profile. Distance is relative to the first shot point.

\begin{tabular}{|l|l|l|l|l|l|l|}
\hline Profile \# & Orientation & $\begin{array}{l}\text { Length of } \\
\text { geophone } \\
\text { Profile } \\
(\mathrm{m})\end{array}$ & $\begin{array}{l}\text { Length of } \\
\text { shot Point } \\
\text { Profile } \\
(\mathrm{m})\end{array}$ & $\begin{array}{l}\text { No. of } \\
\text { shots }\end{array}$ & $\begin{array}{l}\text { No. of } \\
\text { CDPs }\end{array}$ & $\begin{array}{l}\text { Maximum } \\
\text { fold }\end{array}$ \\
\hline Profile 1 & S-N & 138 & 158 & 83 & 147 & 59 \\
\hline
\end{tabular}

\section{Data Acquisition}

In seismic sections, artifacts can be mistaken for structure when geophones or shots locations have significant elevation or lateral variations, and those variations are not accounted for in processing the data. To properly account for the geometric variations, each shot point and geophone location was surveyed using an electronic distance meter with theoretical accuracies of a few centimeters. In this report, we present graphical images of the geometry of the WVAH profile so that visual correlations between geometry and possible artifacts arising from geometry can be made. The numerical form of the geometrical data is presented in Appendix A.

Along the WVAH profile, geophone elevations varied by about $7 \mathrm{~m}$ over a distance of about $140 \mathrm{~m}$ (Fig. 2). The alignment of geophones varied from a straight line by less than $1.3 \mathrm{~m}$ along the 140-m-long profile (Fig. 3). Variations in shot point elevation (Fig. 4) are similar to those of the geophones. Shot points vary in linearity by less than $0.35 \mathrm{~m}$ (Fig. 5). To increase fold near the ends of the geophone array, we made the shot array longer than the geophone array. There were ten shots beyond the northern and southern ends of the geophone 
array. A total of two shot point locations were not used along the profile due to cultural features. Fold along the WVAH profile was smoothly varying because of the stationary recording array (Fig. 6). Maximum fold of about 59 was obtained in the center of the seismic profile and decreased to about 1 at the ends of the profile. Because maximum folds were in the middle of the seismic profile, the most reliable reflection images for the deeper structure should theoretically be near the center of the profile, but the seismic energy was sufficient to image to depths of interest along the entire profile. The data were recorded without acquisition filters so that all possible frequencies would be available.

\section{Seismic Data Processing}

Both reflection and refraction data were acquired simultaneously by using a shoot-through configuration, whereby shots were systematically fired through

the stationary recording array. With this acquisition setup, both reflection and refraction data are available for processing.

\section{Seismic Refraction Velocity Analysis}

In the refraction data processing, we used a seismic tomographic inversion method developed by Hole (1992), whereby, first arrivals on each seismic trace were used to measure detailed velocities from depths ranging from about $1 \mathrm{~m}$ below the surface to about $40 \mathrm{~m}$ depth. For greater depths, velocities needed in seismic reflection stacking were determined using semblence, parabolic methods, and apriori knowledge of the local geology. We used the velocities derived from these methods to convert the reflection time-images to depth-images and to migrate the seismic reflection images.

\section{Seismic Reflection Processing}

Seismic reflection data processing was accomplished on a Sun Sparc $20^{\mathrm{TM}}$ computer using an interactive seismic processing package known as ProMAX ${ }^{\mathrm{TM}}$. The following steps were involved in data processing:

Geometry Installation

Lateral distances and elevations were used to define the geometrical set up of each profile. We installed the electronically measured geometries into the ProMAX ${ }^{\mathrm{TM}}$ processing package so that shot and receiver elevations and locations could be accounted for in the processing routine.

\section{Trace Editing}

Occasionally, bad coupling between the geophones and the ground, malfunctioning geophones, or cultural noise close to the seismic receivers resulted in unusually noisy traces at those locations. Traces representing those locations were edited. However, such traces were not always unsuitable for each shot gather; therefore, independent trace editing was employed for each shot gather. 


\section{Bandpass Filtering}

Most of the data of interest for seismic imaging and velocity measurement are between 25 and $200 \mathrm{~Hz}$, and most of the undesirable seismic data, such as surface waves and shear waves, were below about $35 \mathrm{~Hz}$. We used a final bandpass filter with a low cut of $30 \mathrm{~Hz}$ to remove most surface and shear waves and as cultural noise (prestack frequencies $=40-80-600-1200$; post stack frequencies $=50-100-600-1200$ or $75-150-600-1200 \mathrm{~Hz}$ ).

\section{Gain Correction}

Automatic gain correction (AGC $=100)$ was applied to the pre-stack data.

\section{F-K Filtering}

Not all surface waves were removed by simple bandpass filtering. To remove those surface waves and air waves that were not removed by bandpass filtering, we used an FK filter (FK velocity $=90-400 \mathrm{~m} / \mathrm{s}$, FK frequency $=1-600 \mathrm{~Hz}$ ).

\section{Timing Corrections}

Although the shotgun source electronically triggers the seismographs, there are small $(\sim 2 \mathrm{~ms})$ delays between the electrical trigger and the actual shotgun explosions. We corrected for the delays by removing a constant $2 \mathrm{~ms}$ from the start time of each shotgather.

Velocity Analysis

Velocities in the shallow section ( $\sim 1 \mathrm{~m}$ to $\sim 50 \mathrm{~m}$ ) were determined using velocity inversion techniques, but velocities in the deeper section were determined using shotgathers and CDP stacks.

\section{Elevation Statics}

Elevation statics were also employed to correct for variations in elevations using the electronically determined locations and velocities that were derived from the refraction velocity analysis.

\section{Moveout Correction}

Due to progressively greater traveltimes for the seismic waves to reach sensors that were progressively farther from each shot point, there was a delay (moveout) for each seismic arrival on the seismic record. To sum (stack) the data at each common depth point (CDP), a correction was made for the moveout using velocities obtained from the velocity analysis.

\section{Muting}

To remove refractions and other arrivals that were not completely removed using filtering techniques, we used trace muting before and after stacking.

Stacking

To enhance the seismic signal at each location, individual reflections were summed together in a process called stacking.

Depth Conversion

For stacked seismic reflection sections that were not migrated, we converted the time sections to depth sections using RMS velocities 
converted from the velocity analysis described above in the velocity section.

\section{Migration}

Due to the presence of numerous faults and diffraction points in the subsurface, diffraction hyperbolae were observed throughout the section. We used pre-stack depth migration, a mathematical process that moves seismic energy (such as diffractions) back to their correct position in the subsurface, to collapse the diffraction hyperbolae.

\section{Seismic Refraction Velocities}

We inverted first-arrival refractions to generate a velocity model of the shallow subsurface (Fig. 7). P-wave velocities ranged from less than $500 \mathrm{~m} / \mathrm{s}$ near the surface to more than $4000 \mathrm{~m} / \mathrm{s}$ at about $50 \mathrm{~m}$ depth. In general, velocities are higher on the northern end of the seismic profile than on the southern end, where surficial velocities are less than $500 \mathrm{~m} / \mathrm{s}$. North of meter 60 , velocity contours are nearly horizontal, and there is a pronounced velocity increase across an apparent north-dipping structure. The $1500 \mathrm{~m} / \mathrm{s}$ velocity contour, which often correlates with the water table (Schon, 1996; Catchings, et al., 1998; 1999; Gandhok et al., 1999), is outlined in white (Fig. 7). Because the Santa Monica fault is a known barrier to water flow (Hill et al., 1979), the disruption of the $1500 \mathrm{~m} / \mathrm{s}$ velocity contour is consistent with a decrease in the depth of the water table to the south. The higher velocities (2500 to $4500 \mathrm{~m} / \mathrm{s}$ ) also decrease across the structure in question, suggesting that these units are probably fractured, broken, or not present south of meter 40 of the seismic profile.

\section{Seismic Reflection Images}

Migrated seismic reflection images of the upper $\sim 200 \mathrm{~m}$ are shown in figures $8 \mathrm{a}$ and $8 \mathrm{~b}$ at minimum frequencies of $75 \mathrm{~Hz}$ and $50 \mathrm{~Hz}$, respectively. These data show relatively strong, slightly south-dipping, sub-horizontal reflectors in the upper $20 \mathrm{~m}$ across most of the profile. Near the southern end of the profile, however, these near-surface reflectors are either terminated or dip back northward. From about $20 \mathrm{~m}$ below ground surface (bgs) to about $75 \mathrm{~m}$ bgs on the northern end of the profile, weaker, but clearly defined subhorizontal reflectors are observed across most of the seismic profile. These reflectors are disrupted along a north-dipping feature from about meter 100 (75 $\mathrm{m}$ bgs depth) of the seismic profile to the beginning of the seismic profile $(0 \mathrm{~m}$ depth). Below the north-dipping structure, the reflections appear to be largely north-dipping and irregular. The most prominent of these north-dipping reflections dips about 20 degrees (meter 100 and $75 \mathrm{~m}$ bgs depth. We suggest that this relatively higher-amplitude reflection is generated from the fault plane of the Santa Monica thrust fault. Below about $75 \mathrm{~m}$ depth (bgs), most reflectors

are not well imaged; however, the reflectors appear to be largely sub-horizontal. The poor image below the proposed fault plane probably results from loss of higher frequencies below the fault plane reflector.

At several locations along the seismic profile, there appear to be offsets of reflections across vertical lines, suggesting near-vertical faulting. An apparent near-vertical fault offsets reflectors from the surface to at least $100 \mathrm{~m}$ depth near 
meter 100, where it apparently intersects and is offset by the 20-degree-dipping (Santa Monica thrust?) fault. A second apparent near-vertical fault is located at about meter 120, but it appears not to extend to the near surface, apparently terminating at about $25 \mathrm{~m}$ bgs. There also appear to be other less prominent near-vertical faults between meters 35 and 75 .

An interpretation of fault relations is shown in figures $9 \mathrm{a}$ and $9 \mathrm{~b}$. We suggest the presence of a faulting zone between the 30-degree-dipping fault and the 20-degree-dipping fault that includes both low-angle and high-angle faults.

\section{Combined Velocity/Reflection Images and Interpretation}

Figure 10a shows the seismic velocity inversion model from figure 7 is superimposed on the reflection image from figure 8 . These data show that the strong reflectors within the upper $20 \mathrm{~m}$ (bgs) correlate with velocities less than $2000 \mathrm{~m} / \mathrm{s}$, suggesting that those reflectors are within the unconsolidated alluvial deposits. Relatively weak reflections below $20 \mathrm{~m}$ depth correlate with consolidated rocks, perhaps, the Pico Fm as suggested by Pratt et al., (1998). The deeper reflectors with velocities above about $4000 \mathrm{~m} / \mathrm{s}$ are probably localized high-velocity rocks such as the Santa Monica slate (Gibbs et al., 2000). However, the velocity model suggests that the higher-velocity rocks $(\sim 4000 \mathrm{~m} / \mathrm{s})$ do not extend to the southern end of the profile, suggesting perhaps that the highervelocity rocks may be related to the higher topography along the profile (Fig. 10). Gibbs et al. (2000) also acquired stratigraphic and velocity data from two nearby wells (Fig. 1b). We project one of the wells (well WVAS) southwestward onto the seismic profile in an attempt to compare the seismic images with known stratigraphy (Fig. 10b). Such projections are difficult to do because the strikes and dips are not well known. However, we chose to project the reflection image onto the seismic image on the basis of the topography, whereby well WVAS was placed onto the seismic profile relative to its distance from the 266-ft contour (see Figs. $1 b$ and $10 b)$.

Comparison of the borehole data with the seismic reflection and refraction images suggests a series of unconsolidated sediments and sedimentary rocks, with detritus of the Santa Monica slate at similar depths as indicated by the velocity data (Fig. 10b). At shallow depths, the borehole and seismic data suggest that the Santa Monica thrust fault offsets various units of sedimentary rocks.

\section{Comparison with Other Imaging Studies}

A seismic reflection profile was previously acquired across the Wadsworth VA Hospital property (Dolan and Pratt, 1997; Pratt et al., 1998) along the same transect as the profile presented in this report. We refer to the previously acquired profile as the Mini-sosie profile, in reference to the seismic source used. The Mini-sosie profile used a different source (two earth tampers-surface sources), different acquisition equipment (12 28-Hz clustered geophones), and different acquisition parameters (2.53 m geophone and shot spacing; $2.53-\mathrm{m}$ source-sensor offset; 80-240 Hz filters) than the data presented in this report. In contrast, sources (8-gauge shotgun buried blasts), acquisition equipment (singleelement, $40-\mathrm{Hz}$ geophone), and acquisition parameters (shot and sensor $=2.0 \mathrm{~m}$ 
apart; 1-m source-sensor offset; no filters) for the WVAH profile were designed for more detailed imaging.

The seismic reflection images for both profiles are shown in figure 11 .

Both seismic images show sub-horizontal reflections depicting similar structure in the upper $50 \mathrm{~m}$. Similar apparent folding and disruption of these reflections are indicated on the northern end of the profiles. On the southern end of the profile, however, the two profiles show differing reflections. The Mini-sosie profile does not show continuous sub-horizontal reflections across the southernmost $50 \mathrm{~m}$ of the profile, but our profile does show such reflections. Both profiles show evidence of north-dipping reflections below about $50 \mathrm{~m}$ depth along the southernmost $50 \mathrm{~m}$ of the profile. Pratt et al. (1998) interpreted the lack of continuous reflections along the southern end of the Mini-sosie profile as evidence for an $\sim 30^{\circ}$-dipping Santa Monica fault zone (Fig. 12). Their fault interpretation is consistent with the abrupt change in velocities shown in figure 7 and the disruption of reflections shown in figure 8. However, our data suggest that the fault dips at a lower angle $\left(20^{\circ}\right)$ and is deeper than the interpretation based on the Mini-sosie data. Although we cannot rule out the possibility that there may be two faults, one dipping at about $20^{\circ}$ and the other dipping at about $30^{\circ}$, or that there may simply be a fault zone between these two angles, this apparent discrepancy in fault dip may be related to seismic data acquisition and processing differences. Differences in the velocities used to stack the seismic data can cause loss of resolution and changes in dip angle. Our velocity inversion model shows that velocities greatly decrease on the southern end of the profile. If the Mini-sosie data were stacked using a laterally constant velocity, it would limit the resolution of reflectors, alter the angle of reflections, and place reflections at artificially shallower depths near the southern end of the profile. Because the resolution of the Mini-sosie image appears to be degraded on the southern end of the profile, we suggest that the $20^{\circ}$-angle of dip is probably more likely for the near-surface part of the Santa Monica fault plane.

Dolan and Pratt (1997) and Pratt et al. (1998) also presented results from a paleoseismological trench that was dug within about $5 \mathrm{~m}$ of the Mini-sosie profile (Figure 12). Their interpretation was based on a combination of observations within the trench and the Mini-sosie data. We superimposed their interpretation on the seismic reflection image from this study to compare the two interpretations (Fig. 13a,b). Their interpretation is consistent with our seismic section, particularly with respect to fault relations such as the near-vertical faults near meter 50 and the general trend of the Santa Monica thrust fault. The general tend of the Dolan and Pratt's (1997) Late Holocene alluvium (Fig. 12) is also consistent with near-surface reflections in the higher-frequency seismic image (Fig. 13a). Dolan and Pratt's (1997) interpretation of layering above the fault plane is similar to our reflection image, and their interpretation of the fault plane coincides with less regular layering when viewed at lower frequencies (Fig. $13 b)$.

\section{Comparison with Borehole Velocity Measurements}

Both borehole (Gibbs et al., 2000) and surface measurements (this study) of velocities in the vicinity of the Wadsworth VA Hospital are available and can be compared. There are differences between the acquisition and the calculation 
methods of Gibbs et al.(2000) and those of this study. Our velocity model was developed from a tomographic inversion scheme (Hole, 1992) that uses as many as several hundred measurements in each $2 \mathrm{~m}$ by $2 \mathrm{~m}$ grid of the velocity model. Gibbs et al. (2000) use a least-square fit to a limited number (usually less than 10) of first arrivals. Our velocity model also uses gradients and averages the velocities over 2-m vertical and horizontal distances; whereas the Gibbs et al. (2000) model utilizes borehole lithology to aid in segmenting the first arrivals on the basis of depth. Small negative gradients, if present, are averaged in our model and are not usually observed.

The acquisition method also differs between the two data sets. Our surface-based method is described above in the acquisition section of this report. In general, we use 2-m shot and geophone spacing on the surface to measure velocities. Conversely, Gibbs et al. (2000) use a surface source and a down-hole geophone to measure travel times at specific depths. The surface source was offset $4 \mathrm{~m}$ from the hole, and measurements were made every $2.5 \mathrm{~m}$ in depth. Because of the interpretative method used and the limited number of individual measurements in a given depth range (Fig. 14), there is a range of possible velocities in the Gibbs et al. (2000) model (Fig. 15).

The velocities differ between the two models because of a number of factors, including differences in geographical location, averaging in both models, and interpretations in Gibbs et al.'s model, however, the overall velocities are similar. The seismic profile was located southwest and southeast of the two boreholes reported by Gibbs et al. (2000), but seismic profile was not located within several hundred meters of either well. Differences in velocity are, therefore, probably related to location. To compare the borehole and surfacebased velocities, we compare velocities of the closest borehole (WVAS) with the seismic profile at about meter 40 of the seismic profile, the approximate distance from the 266-ft contour for both the borehole and seismic profile (Fig. 1b).

In both models, average compressional velocities in the upper $5 \mathrm{~m}$ are approximately $500 \mathrm{~m} / \mathrm{s}$ (average southern well), and from about 5 to $10 \mathrm{~m}$ depth, the average velocities are about $1000 \mathrm{~m} / \mathrm{s}$. Gibbs et al. (2000) reported a low-velocity zone ( $\sim 700 \mathrm{~m} / \mathrm{s})$ from about 10 to $20 \mathrm{~m}$ depth in the northern well but higher velocities $(\sim 1768 \mathrm{~m} / \mathrm{s})$ in the southern well. Our velocity model is consistent with the southern well in this depth range (average - 1800 m/s). From about 22 to $45 \mathrm{~m}$ depth, the northern well is interpreted to have velocities ranging from about $1750 \mathrm{~m} / \mathrm{s}$ to about $1900 \mathrm{~m} / \mathrm{s}$ (Fig. 15b), and the average velocity for the corresponding depth in our model $2100 \mathrm{~m} / \mathrm{s}$ (Fig. 7). At about 45 $\mathrm{m}$ depth, Gibbs et al. (2000) show a zone with a wide range of possible velocities (as high as $4000 \mathrm{~m} / \mathrm{s}$ ), and our velocity model also shows velocities between 4000 and $4500 \mathrm{~m} / \mathrm{s}$ in that depth range. Our model further shows that the highvelocities do not extend to the southern part of the line in the vicinity of the southern well. On the southern end of our profile, both Gibbs et al. (2000) and our data suggest lower velocities $(\sim 1768 \mathrm{~m} / \mathrm{s})$ at similar depths.

\section{Summary}

High-resolution seismic reflection/velocity images acquired across the Santa Monica fault at the WVAH in west Los Angeles show evidence for an $\sim 20^{\circ}$ dipping Santa Monica fault plane in the upper $50 \mathrm{~m}$ near Ohio Avenue. This dip 
angle is about 10 degrees less than that suggested by Dolan and Pratt (1997) and Pratt et al. (1998). The lower dip angle for the Santa Monica fault may indicate greater dip-slip motion on the fault than they previously calculated. The $20^{\circ}$ dip places the surface projection of the Santa Monica fault further south than suggested by Dolan and Pratt (1997) and Pratt et al. (1998), probably in the vicinity of Santa Monica Blvd. (Figure 9). A zone of disrupted reflectors indicates that the thrust fault zone may be in excess of $25 \mathrm{~m}$ thick, with dip angles between 20 and 30 degrees.

The images also show evidence for near-vertical faults, some of which apparently cut the Santa Monica fault plane. Dolan and Pratt (1997) and Pratt et al. (1998) also found paleoseismological evidence for near-vertical faults overlying the Santa Monica thrust fault, but they did not have data at sufficient depths to determine the relationship between the thrust fault and the nearvertical faults. Such near vertical faults suggest that both dip-slip and thrust components of faulting are present and have probably been ongoing within the Santa Monica fault zone. For purposes of hazard assessment, both types of faults and their locations with respect to buildings must be considered.

Although Dolan and Pratt (1997) show that the dip-slip faults have predominantly east-west orientations, some of these faults may be related to the northwest-trending strike-slip faults (Charmocke, Overland, and NewportInglewood) that apparently merge with the Santa Monica thrust fault in the West Los Angeles area (Fig. 1a).

Seismic velocity measurements show evidence for an abrupt decrease in velocity near locations where paleoseismological trenching studies have shown evidence for near-vertical faulting. This reduction in velocity is probably the result of broken and fractured strata and a thicker accumulation of unconsolidated sediments. Velocities decrease by about $500 \mathrm{~m} / \mathrm{s}$ across a zone of near-vertical faulting on the southern end of the seismic profile, where surficial velocities are less than $500 \mathrm{~m} / \mathrm{s}$ at the surface. Gibbs et al. (2000) found that these low compressional velocities correspond to shear-wave velocities between $184 \mathrm{~m} / \mathrm{s}$ and $286 \mathrm{~m} / \mathrm{s}$. Compressional velocities in excess of $4000 \mathrm{~m} / \mathrm{s}$ were measured at depths of about $50 \mathrm{~m}$ beneath the central part of the seismic profile. These high velocities probably result from the Santa Monica slate, which was found in borehole WVAN at depths of between 50 and $60 \mathrm{~m}$ bgs approximately $600 \mathrm{~m}$ northwest of the seismic profile (Gibbs et al., 2000). Comparisons between borehole-derived and surface-derived velocity measurements show good general agreements, but these comparisons also points out limitations of each method. In general, the borehole measurements suffer from too few data points in too limited an area, and the surface measurements, while consisting of a large number of measurements, tend to average the velocities over several meters depth.

The Santa Monica fault is a known water barrier (Hill et al., 1979). Our velocity measurements show an approximately 15-m increase in depth of the $1500 \mathrm{~m} / \mathrm{s}$ velocity contour across the near-vertical fault zone on the southern end of our seismic profile. Because the $1500 \mathrm{~m} / \mathrm{s}$ velocity contour is often indicative of the water table in unconsolidated sediments, we take this to be indirect evidence that the fault zone acts locally as a ground water barrier.

The Santa Monica fault poses a clear potential hazard for the Los Angeles region. Seismic imaging studies, combined with borehole and trenching studies, 
provide an efficient way to better understand the hazard by locating faults relative to critical infrastructures, by measuring velocities that are needed for engineering purposes, by identifying the faulting relationships, and by determining sites suitable for further trenching studies.

\section{Acknowledgments}

We thank Tom Burdette, Ed Criley, Paul Davis, Katharine Favret, Gary Fuis, Andy Gallardo, Janice Murphy, and the UCLA geophysics class for field assistance. We thank John Hamilton for surveying the shots and recording sites. We thank the Wadsworth Veterans Administration Hospital for access. Funding was provided, in part, by the USGS Earthquake Hazards program and the University of Southern California. Reviews by Shane Detweiler, Janice Murphy, Rob Williams, Bill Stephenson, and Clodagh Heverin are greatly appreciated.

\section{References}

Catchings, R. D., E. Horta, M. R. Goldman, M. J. Rymer, and T. R. Burdette, 1998, High-Resolution Seismic Imaging For Environmental and Earthquake Hazards Assessment at the Raychem Site, Menlo Park, California, US Geological Survey Open-file Report 98-146, 37 pp.

Catchings, R. D., M. R. Goldman, G. Gandhok, E. Horta, M. J. Rymer, P. Martin, and A. Christensen, 1999, Structure, Velocities, and faulting Relationships Beneath San Gorgonio Pass, California: Implications for Water Resources and Earthquake Hazards, US Geological Survey Open-file Report 99-568, 53 pp.

Crook, R., R. Proctor, and C. E. Lindvall, 1983, Seismicity of the Santa Monica and Hollywood faults determined by trenching: U. S. Geological Survey Final Technical Report, Contract 14-08-0001-20523, 26 p.

Davis, T. L., and J. S. Namson, 1994, A balanced cross section of the 1994 Northridge earthquake, southern California: Nature, 372, 167-169

Dolan, J. F., K. Sieh, T. K. Rockwell, R. S. Yeats, J. Shaw, J. Suppe, G. Huftile, and E. Gath, 1995, Prospects for larger and more frequent earthquakes in greater metropolitan Los Angeles, California: Science, 267, 199-205

Dolan, J. F. and T. L. Pratt, 1997, High-resolution seismic reflection profiling of the Santa Monica fault zone, west Los Angeles, California, Geophysical Research Letters, 24, 2051-2054 
Dolan, J. F., K. Seigh, T. K. Rockwell, P. Guptill, and G. Miller, 1997, Active tectonics, paleoseismology, and seismic hazards of the Hollywood fault, northern Los Angeles basin, California, Geol. Soc. America Bull., 109, 1595-1616

Gandhok, G., R. D. Catchings, M. R. Goldman, E. Horta, M. J. Rymer, P. Martin, and A. Christensen, 1999, High-Resolution Seismic Reflection/Refraction Imaging from Interstate 10 to Cherry Valley Boulevard, Cherry Valley, Riverside County, California: Implications for Water Resources and Earthquake Hazards, US Geological Survey Open-file Report 99-320, 52 pp.

Gibbs, J. F., J. C. Tinsley, D. M. Boore, and W. B. Joyner, 2000, Borehole velocity measurements and geological conditions at thirteen sites in the Los Angeles, California region, US Geological Survey Open-File Report 00470, $118 \mathrm{pp}$.

Hill, R. L., E. C. Sprotte, R. H. Chapman, G. W. Chase, J. H. Bennett, C. R. Real, R. C. Slade, G. Borchardt, and F. H. Weber, 1979, Earthquake hazards associated with faults in the greater Los Angeles metropolitan area, Los Angeles County, California, including faults in the Santa MonicaRaymond, Verdugo-Eagle Rock, and Benedict Canyon fault zones, US Geological Survey Open-File Report 79-16 LA 204 pp.

Hole, J. A., 1992, Nonlinear high-resolution three-dimensional seismic traveltime tomography, Journal of Geophysical Research, v. 97, p. 6553-6562.

Pratt, T. L., J. F. Dolan, J. K. Odum, W. J. Stephenson, R. A. Williams, and M. E. Templeton, 1998, Multiscale seismic imaging of active fault zones for hazard assessment: A case study of the Santa Monica fault zone, Los Angeles, California, Geophysics, 63, 479-489

Schon, J. H., 1996, Physical Properties of Rocks: Fundamentals and Principals of Petrophysics, Handbook of Geophysical Exploration, Seismic Exploration Vol 18, Elsevier Science, Inc., Tarrytown, N. Y.

Yerkes, R. F. and W. H. K. Lee, 1979, Late Quaternary deformation in the western Transverse Ranges, California: U. S. Geological Survey Circular 799-B, $10 \mathrm{pp}$.

Ziony, J. I., and L. M. Jones, 1989, Map showing late Quaternary faults and 197884 seismicity of the Los Angeles region: U. S. Geological Survey misc.

Field Studies, Map MF-1964, scale 1:250,000 
Ziony, J. I. And R. F. Yerkes, 1985, Evaluating earthquake surface-faulting potential, in Ziony, J.I., ed., Evaluating earthquake hazards in the Los Angeles region - an earth-science perspective: U.S. Geological Survey Professional Paper 1360, 43-91

\section{Figures}

Figure1a. Generalized fault map of the Los Angeles region with the location of the Wadsworth VA Hospital (from Hill et al., 1979)

Figure 1b. USGS topographic map of the West Los Angeles area near the Wadsworth Veterans Administration Hospital. The locations of the WVAH seismic profile (blue line) and boreholes (WVAN and WVAS) are shown within the box. The Mini-Sosie profile and the WVAH profile were approximately coincident. The $266-\mathrm{ft}$ contour is shown dashed as it crosses the WVAH profile.

Figure 2. Geophone elevation along the profile. Elevation is relative to the topographically lowest shot point.

Figure 3. Geophone variation from a straight line connecting the first and last shot point along the profile.

Figure 4. Shot point elevation along the profile. Elevation is relative to the topographically lowest shot point along the seismic profile.

Figure 5. Shot point variation from a straight line connecting the first and last shot point.

Figure 6. Fold as a function of common depth point along the profile.

Figure 7. Seismic velocity inversion model along the WVAH profile. The 1500 $\mathrm{m} / \mathrm{s}$ and $4000 \mathrm{~ms} /$ velocity contours are shown in white and yellow, respectively. The WVAN and WVAS well logs are from Gibbs et al. (2000). The WVAN and WVAS wells are located at least $600 \mathrm{~m}$ northwest and $250 \mathrm{~m}$ northeast, respectively, of the WVAH seismic profile. Well-log descriptions and velocities are shown in figures $15 \mathrm{a}$ and $15 \mathrm{~b}$.

Figure 8a. Stacked and migrated seismic reflection image at WVAH (high frequency $=75-150-6001200$ ).

Figure $8 \mathrm{~b}$. Stacked and migrated seismic reflection image along the WVAH profile (lower frequency $=50-100-600-1200$ ).

Figure 9a. Seismic reflection image along WVAH profile with interpretative faults. Frequency range is 75-150-600-1200. The WVAS well log (from Gibbs et al., 2000) is shown superimposed. 
Figure 9b. WVAH profile with interpretative faults (from this study) and simplified well log (from Gibbs et al., 2000) for the WVAS well. Frequency range $=50-100-600-1200$. See fig. $15 \mathrm{~b}$ for geology explanation

Figure 10. (a) Seismic reflection image of the upper $100 \mathrm{~m}$ along the WVAH profile with the seismic velocity inversion model superimposed. (b) Interpretative geologic model along the WVAH seismic profile based on seismic reflection images, seismic refraction velocities, and well logs. Well logs from Gibbs et al.(2000). The WVAS and WVAN wells are located at least $250 \mathrm{~m}$ northeast and $\sim 600 \mathrm{~m}$ northwest, respectively, of the profile.

Figure 11. (a) Mini-Sosie seismic reflection profile (from Dolan and Pratt, 1997) recorded along the WVAH profile. (b) Seismic profile from figure $9 \mathrm{~b}$ of this study.

Figure 12. Geologic interpretative line drawing based on results from trenching and previous seismic imaging (from Dolan and Pratt, 1997).

Figure 13a WVAH seismic image (higher frequency $=75-1200 \mathrm{~Hz}$ ) with geologic model of Dolan and Pratt. (1997) superimposed (in red). Blue lines show interpreted structure from this study.

Figure 13b WVAH seismic image (low frequency $=50-1200 \mathrm{~Hz}$ ) with geologic model of Dolan and Pratt (1997) superimposed (in red). Blue lines show interpreted structure from this study.

Figure 14a First-arrival picks from borehole velocity measurements of Gibbs et al. (2000).

Figure 14b First-arrival travel time picks for down-hole seismic data acquired at the Wadsworth VA Hospital, northern well (from Gibbs et al., 2000).

Figure 15a Seismic compressional-wave velocity profile and well log for the Wadsworth-VA- South well (from Gibbs et al., 2000). Velocities are determined by least-square fits to data shown in figure 14a. Dashed lines depict plus or minus one standard deviation.

Figure 15b Seismic compressional-wave velocity model for the Wadsworth-VANorth well. The dashed lines represent plus and minus one standard deviation of velocity measurements. The generalized geologic well log is shown to the right. From Gibbs et al. (2000). Note that velocities as high as $4000 \mathrm{~m} / \mathrm{s}$ are possible at depths between 50 and $60 \mathrm{~m}$. 


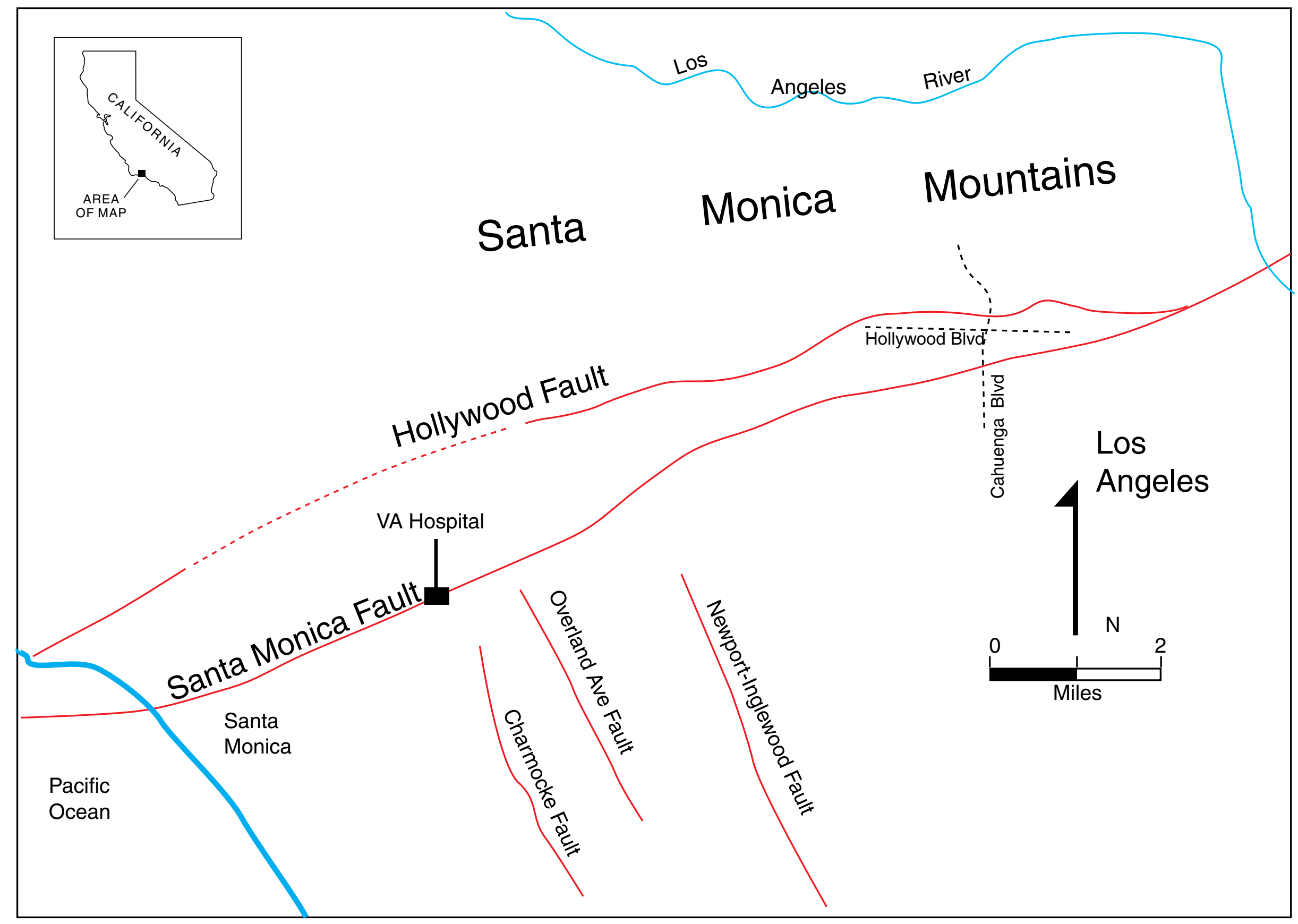

Fig. 1a Generalized fault map of the Los Angeles region with the location of the Wadsworth VA Hospital (from Hill et al., 1979) 


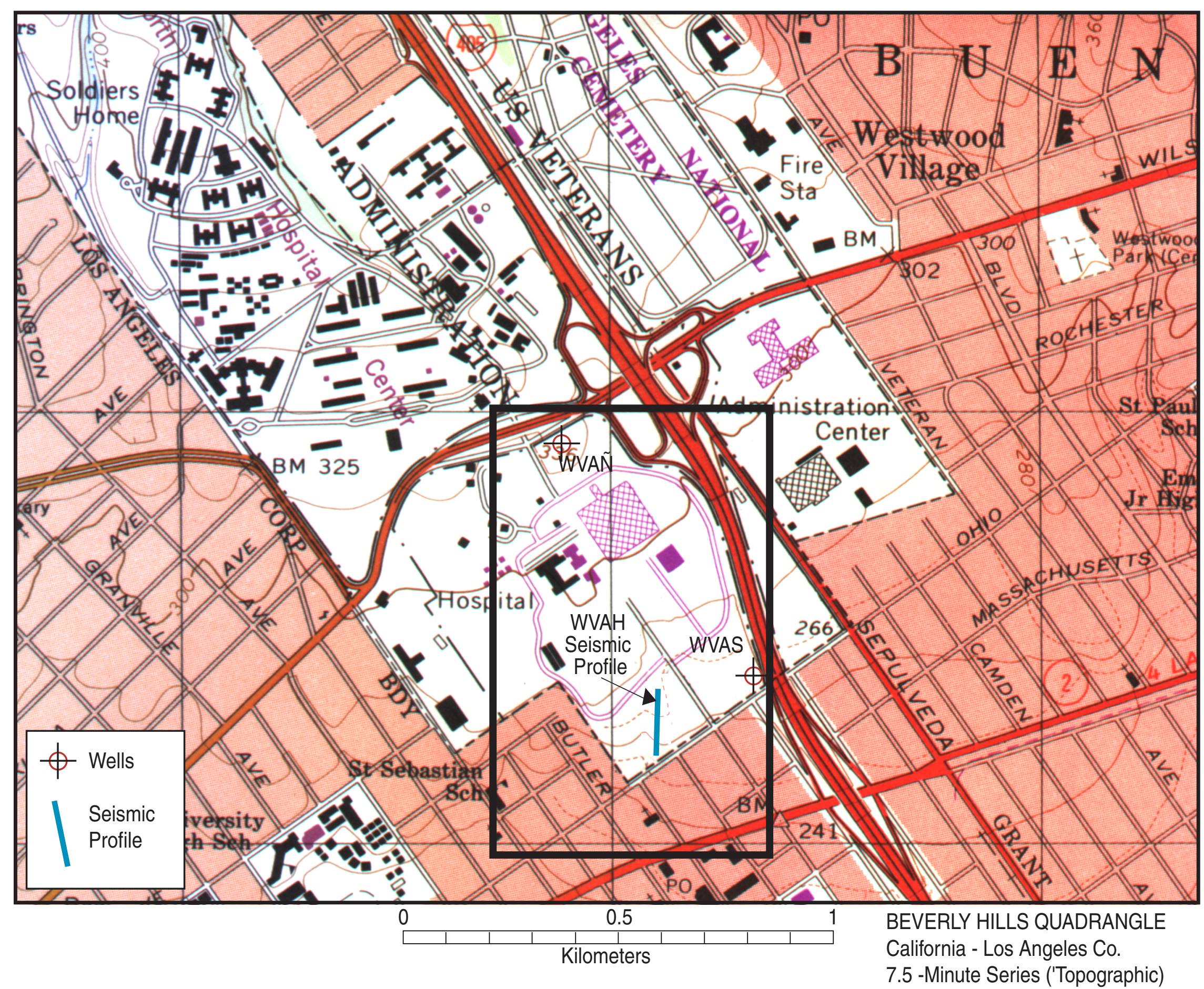

Fig. $1 \mathrm{~b}$ USGS topographic map of the West Los Angeles area near the Wadsworth Veterans Administration Hospital. The locations of the WVAH seismic profile (blue line) and boreholes (WVAN and WVAS) are shown within the box. The Mini-sosie profile and the WVAH profile were approximately coincident. The $266-f t$ contour is shown dashed as it crosses the WVAH profile. 


\section{Wadsworth VA Hospital Profile}

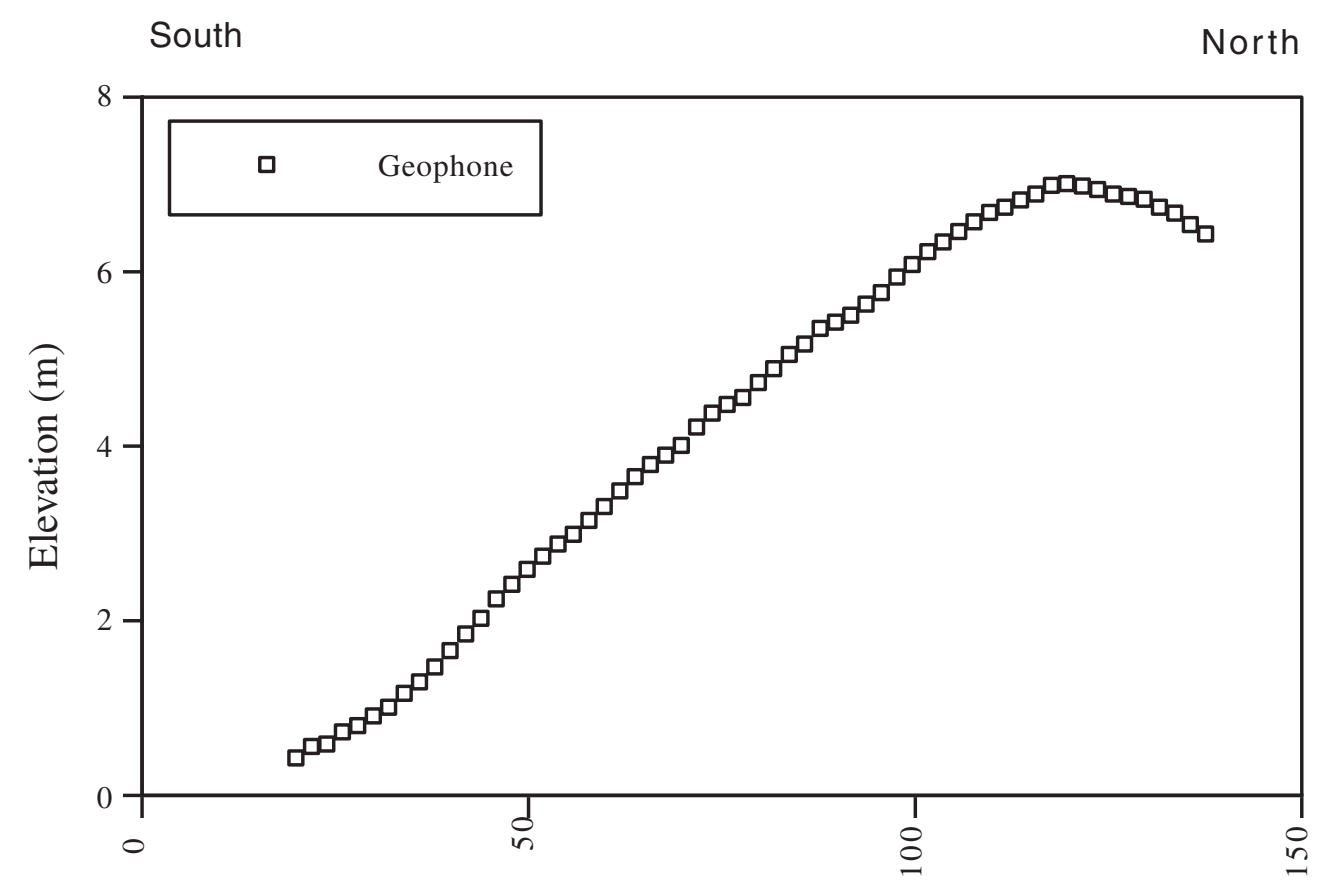

Distance from first shot point (m)

Fig. 2. Geophone elevation along the profile. Elevation is relative to the topographically lowest shot point.

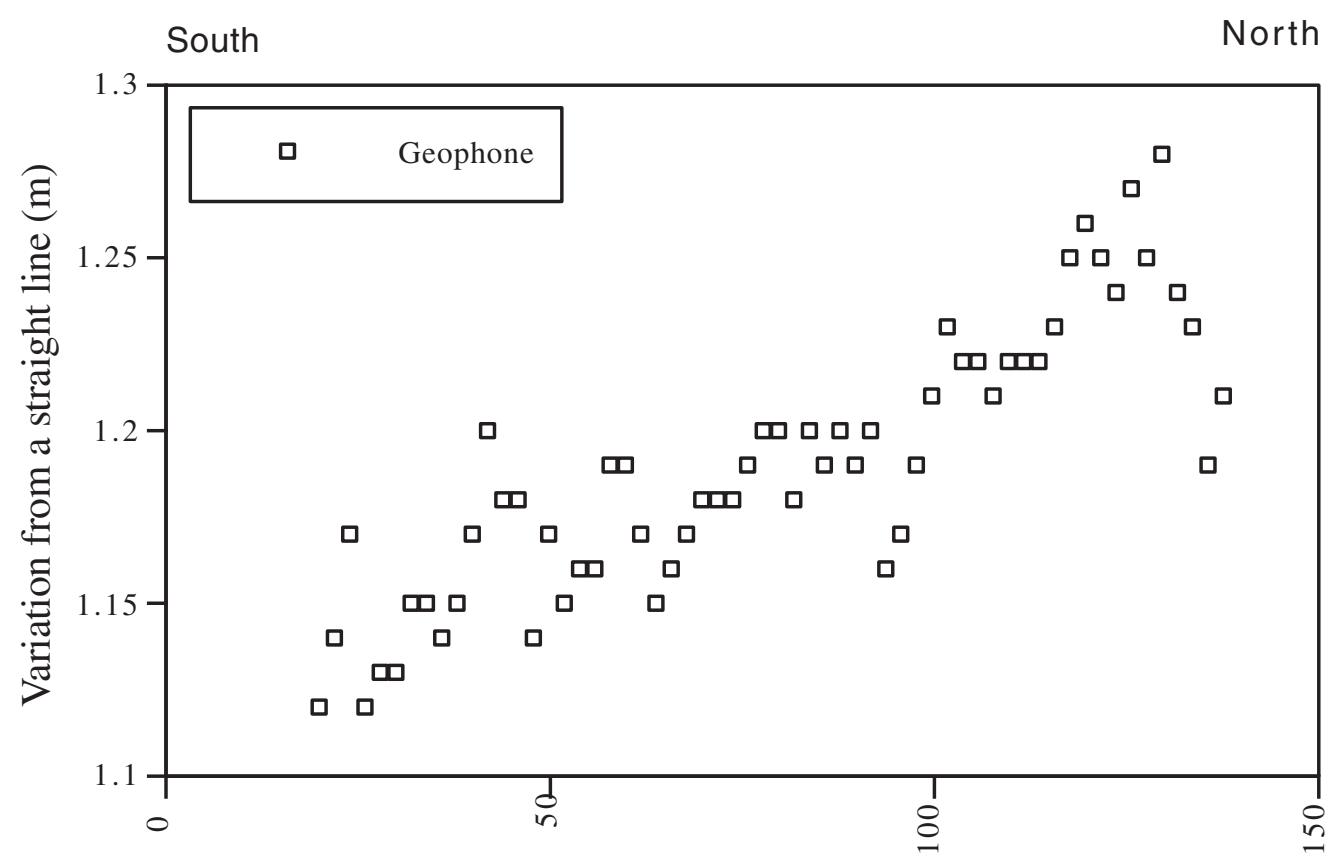

Distance from first shot point (m)

Fig. 3. Geophone variation from a straight line connecting the first and last shot point along the profile. 
Wadsworth VA Hospital Profile

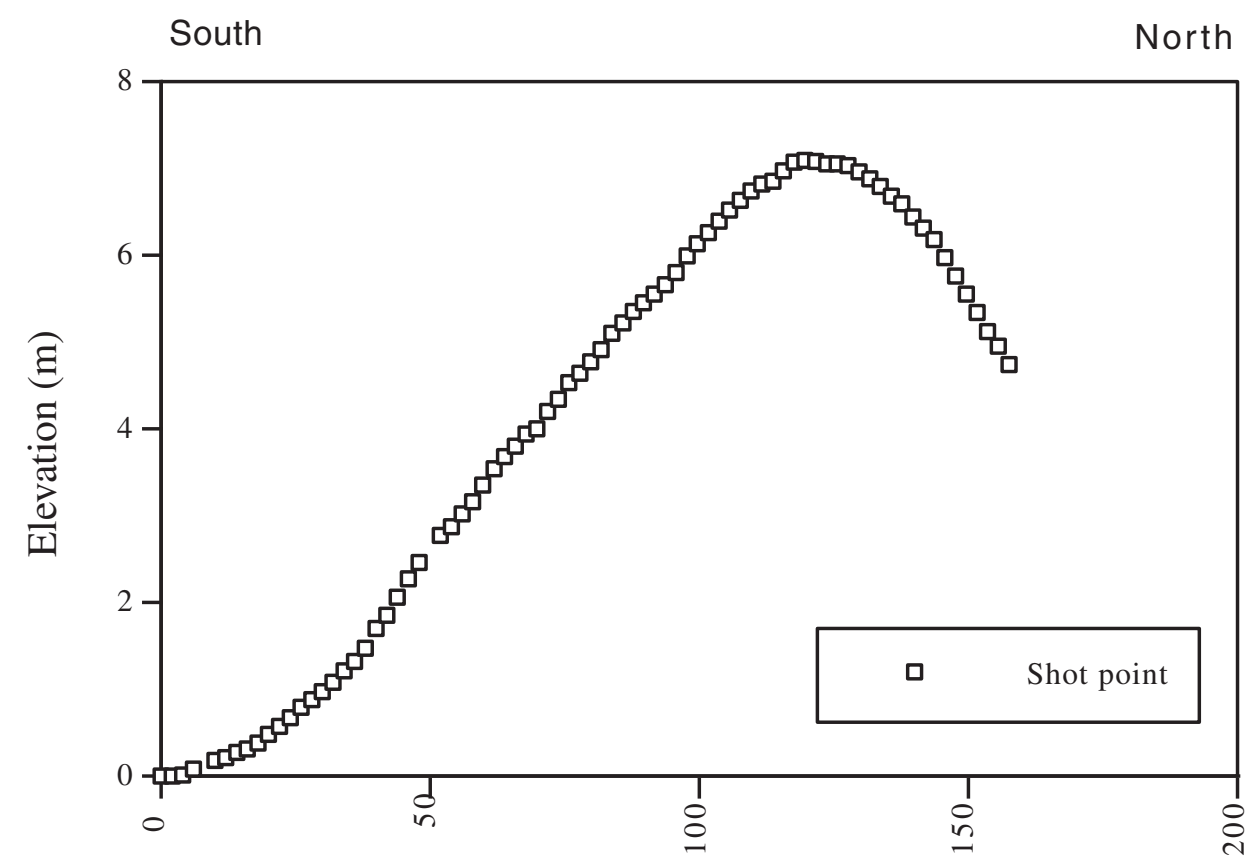

Distance from first shot point (m)

Fig. 4. Shot point elevation along the profile. Elevation is relative to the topgraphically lowest shot point along the seismic profile.

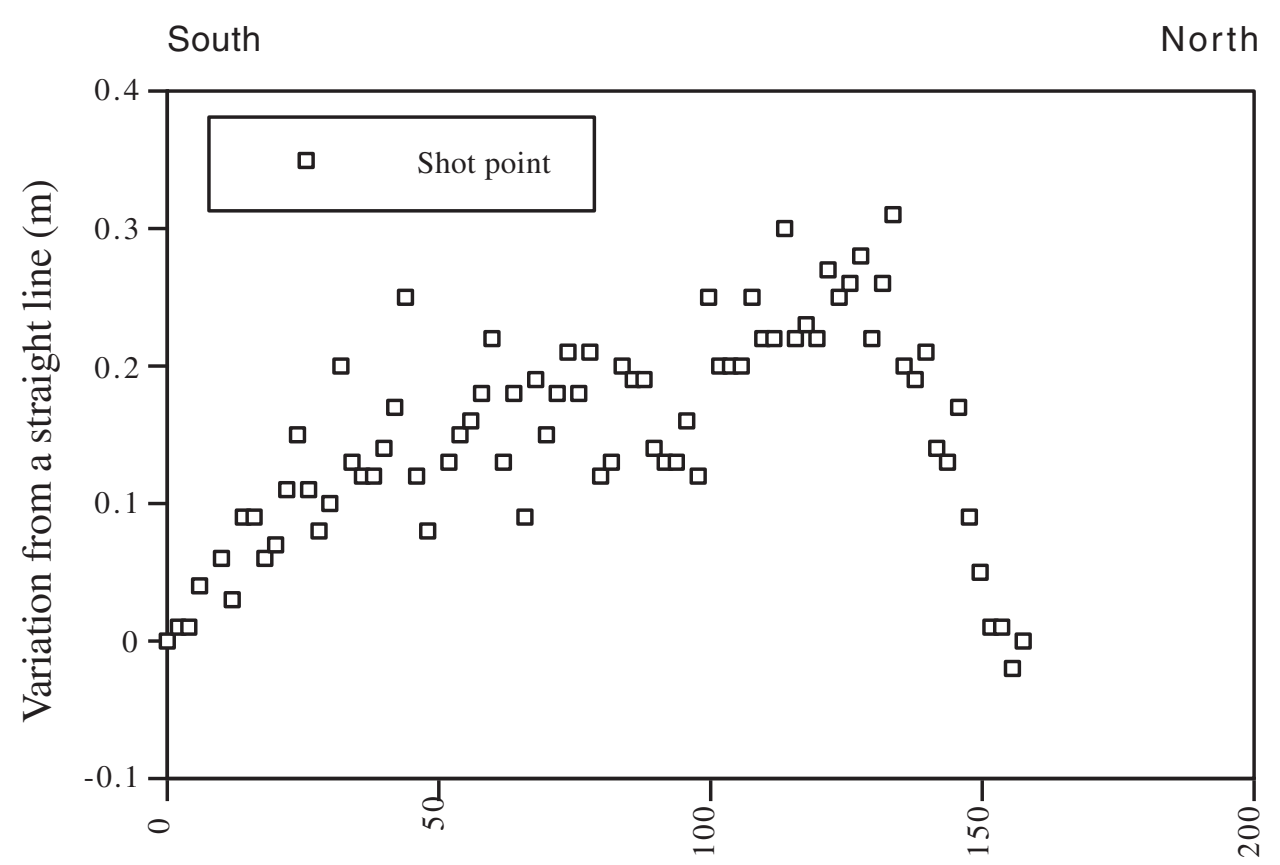

Distance from first shot point (m)

Fig. 5. Shot point variation from a straght line connecting the first and last shot point. 
Wadsworth VA Hospital Profile

South

North

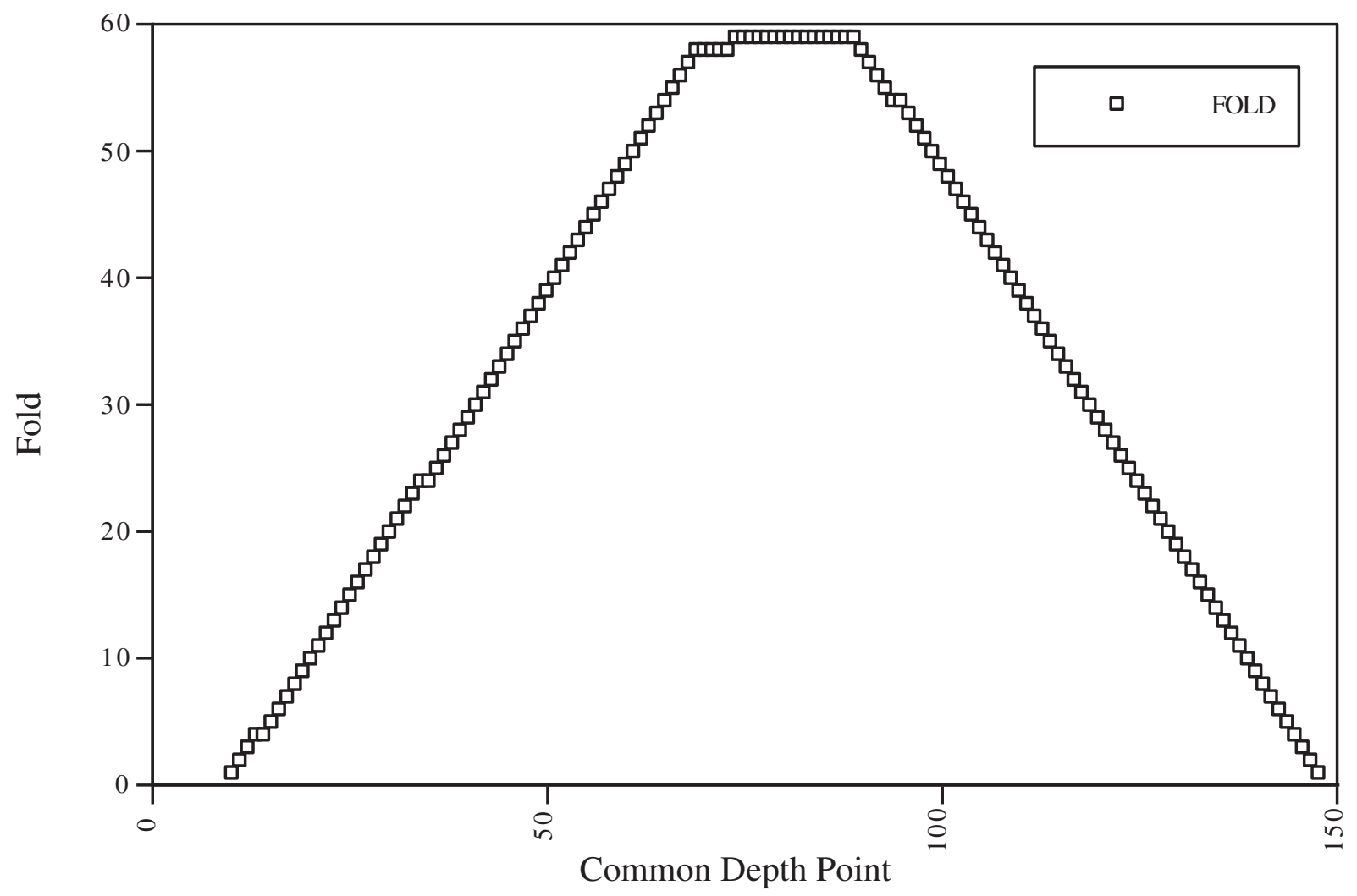

Fig. 6. Fold as a function of common depth point along the profile. 


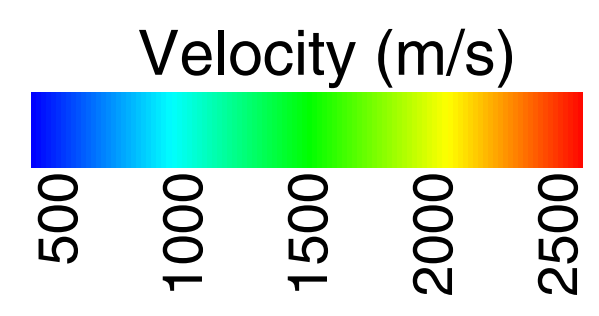

\section{Wadsworth VA Hospital}

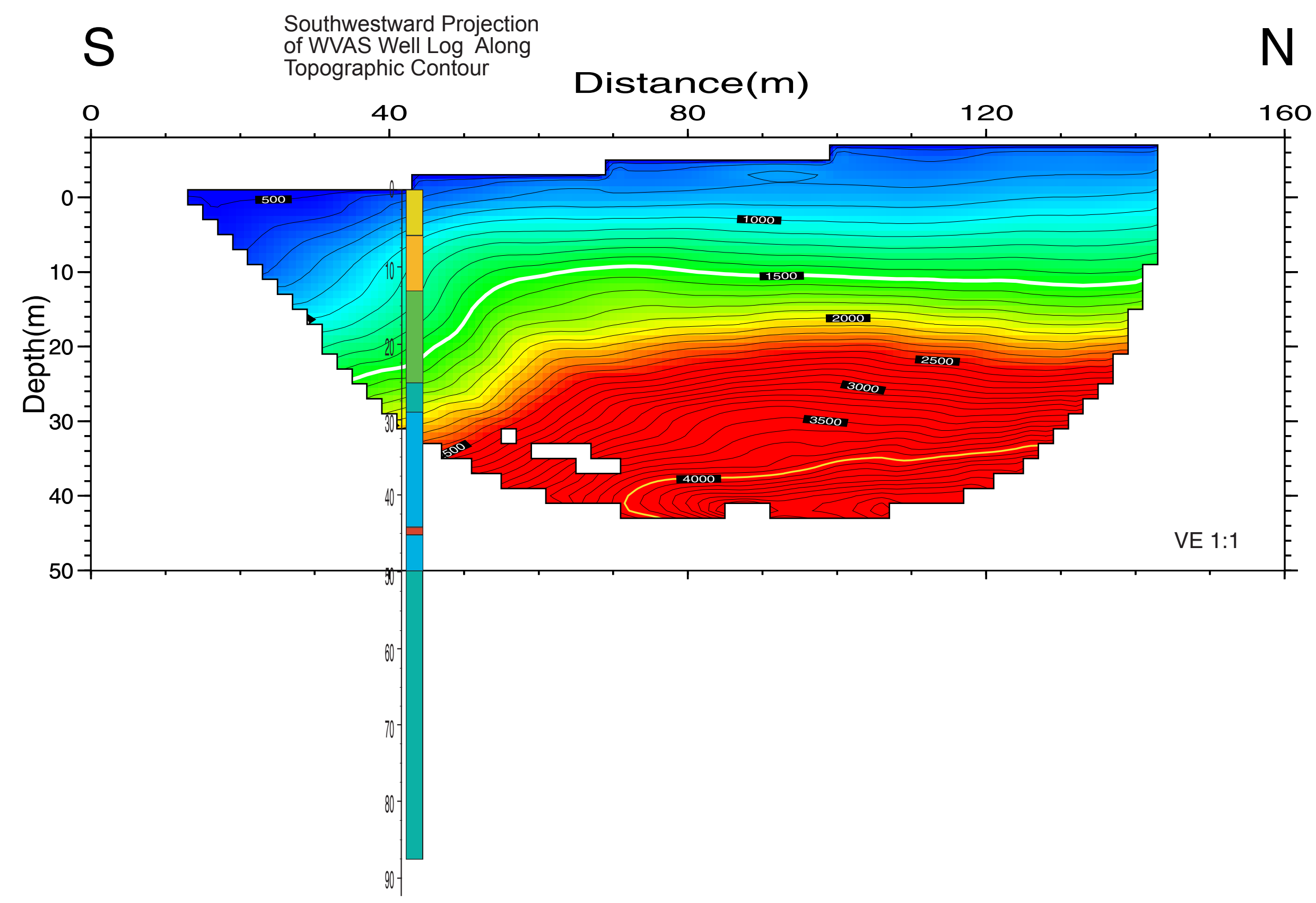

WVAN Well Log

(15 m elevation

(15) north end

of WVAH profile)

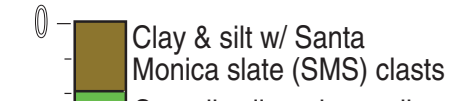

$10^{-}$ Gravelly silt and gravelly

20

Clay w/ clayey sand, silt, and sitty clay w/ SMS pebbles

30

Sand $w /$ trace of silt. Interbedded silt and clay

40 Sand, gravelly sand w/ silt intervals

50

Siltstone $w /$ thin

limestone bed

Shale and slate bedrock (Santa Monica slate) w/

60 quartzite chips

Siltstone, mudstone w/

70 - interbeds of siltstone and shale

80

90

Fig. 7 Seismic velocity inversion model along the WVAH profile. The $1500 \mathrm{~m} / \mathrm{s}$ and $4000 \mathrm{~ms} /$ velocity contours are shown in white and yellow, respectively. The WVAN and WVAS well logs are from Gibbs et al. (2000). The WVAN and WVAS wells are located approximately $600 \mathrm{~m}$ northwest and $250 \mathrm{~m}$ northeast, respectively, of the WVAH seismic profile. Well-log descriptions and velocities are shown in figures $15 \mathrm{a}$ and $15 \mathrm{~b}$. 
$S$
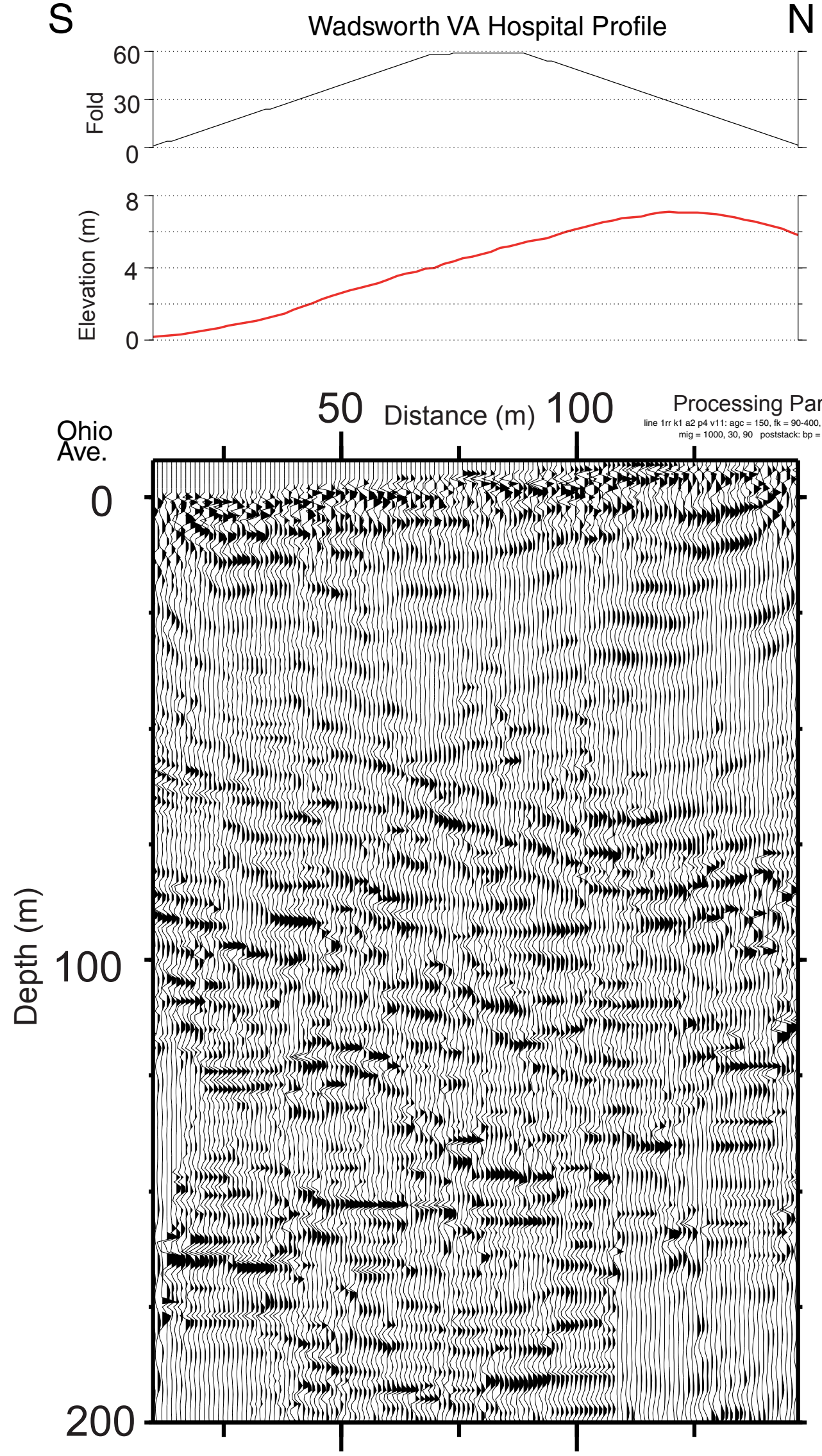

Fig. 8a Stacked and migrated seismic reflection image at WVAH (high frequency $=75-150-6001200$ ). 
$S$
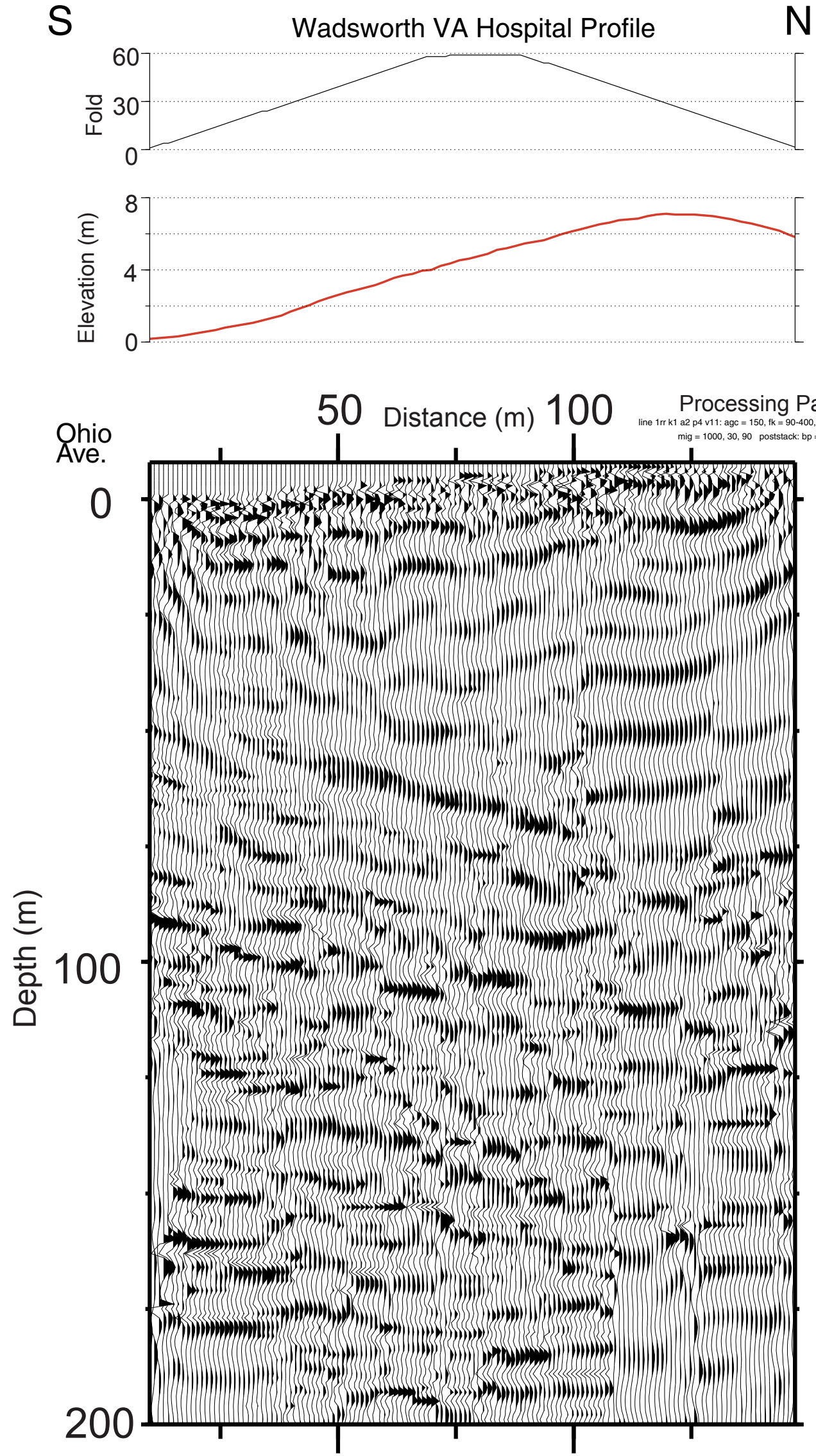

Fig. 8b Stacked and migrated seismic reflection image at WVAH (lower frequency $=50-100-600-1200)$. 

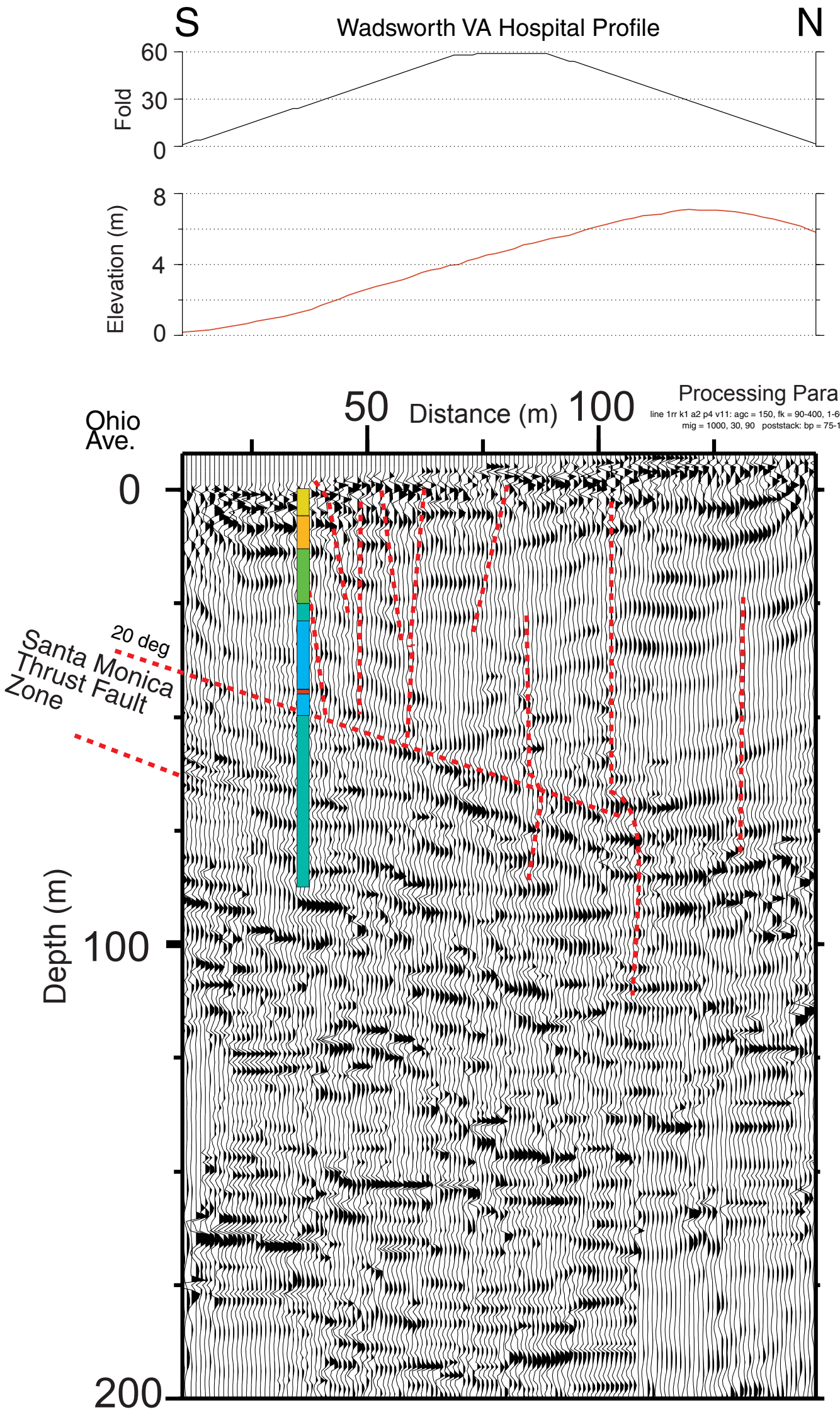

Fig. 9a Seismic reflection image along profile WVAH with interpretative faults. Frequency range is 75-150-600-1200. The WVAS well log is shown superimposed. 

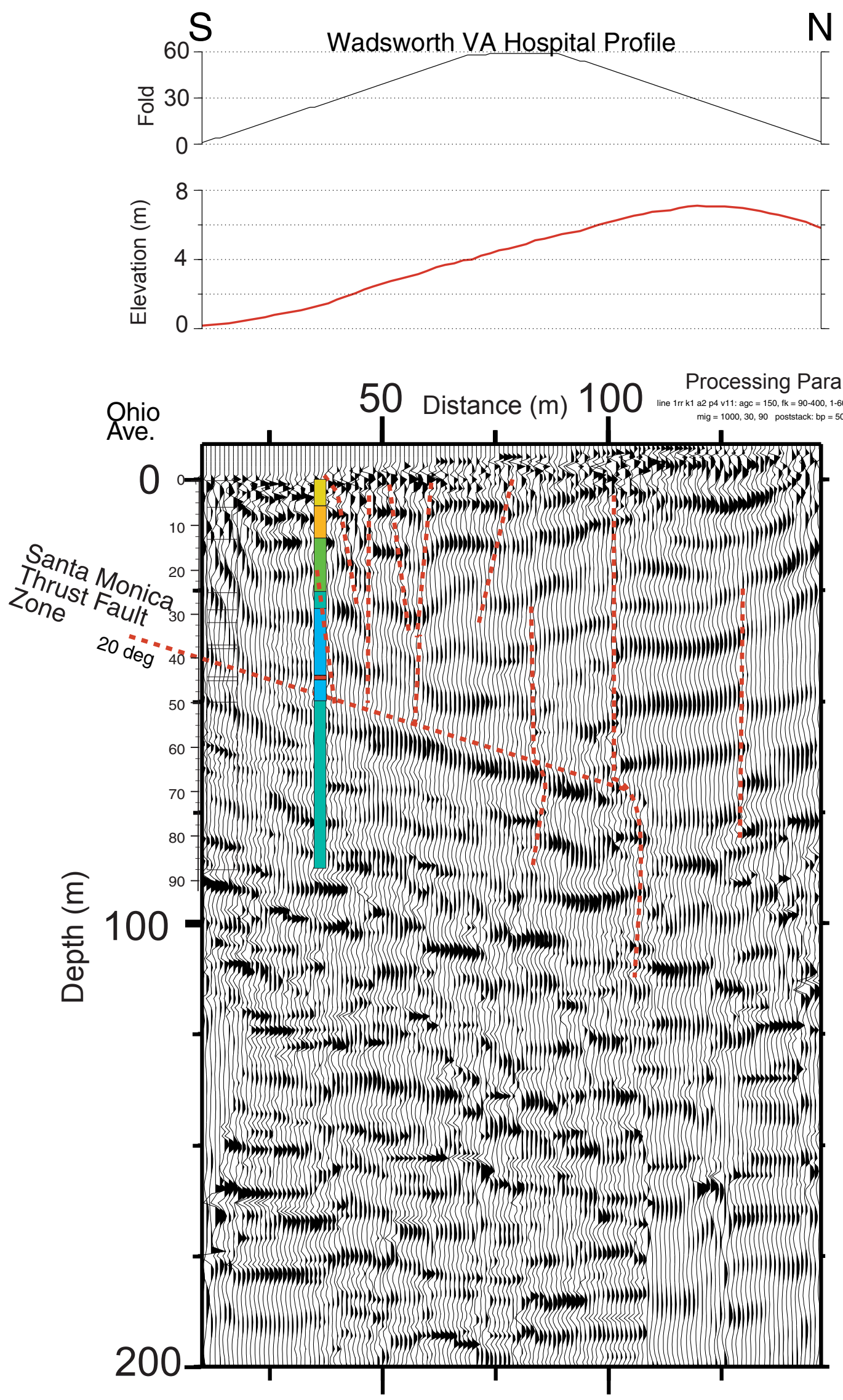

Fig. 9b WVAH profile with interpretative faults and simplified well log for the WVAS well. Frequency range $=50-100-600-1200$. See fig. $15 \mathrm{~b}$ for geology explanation 


\section{South}

Wadsworth VA Hospital Profile

North
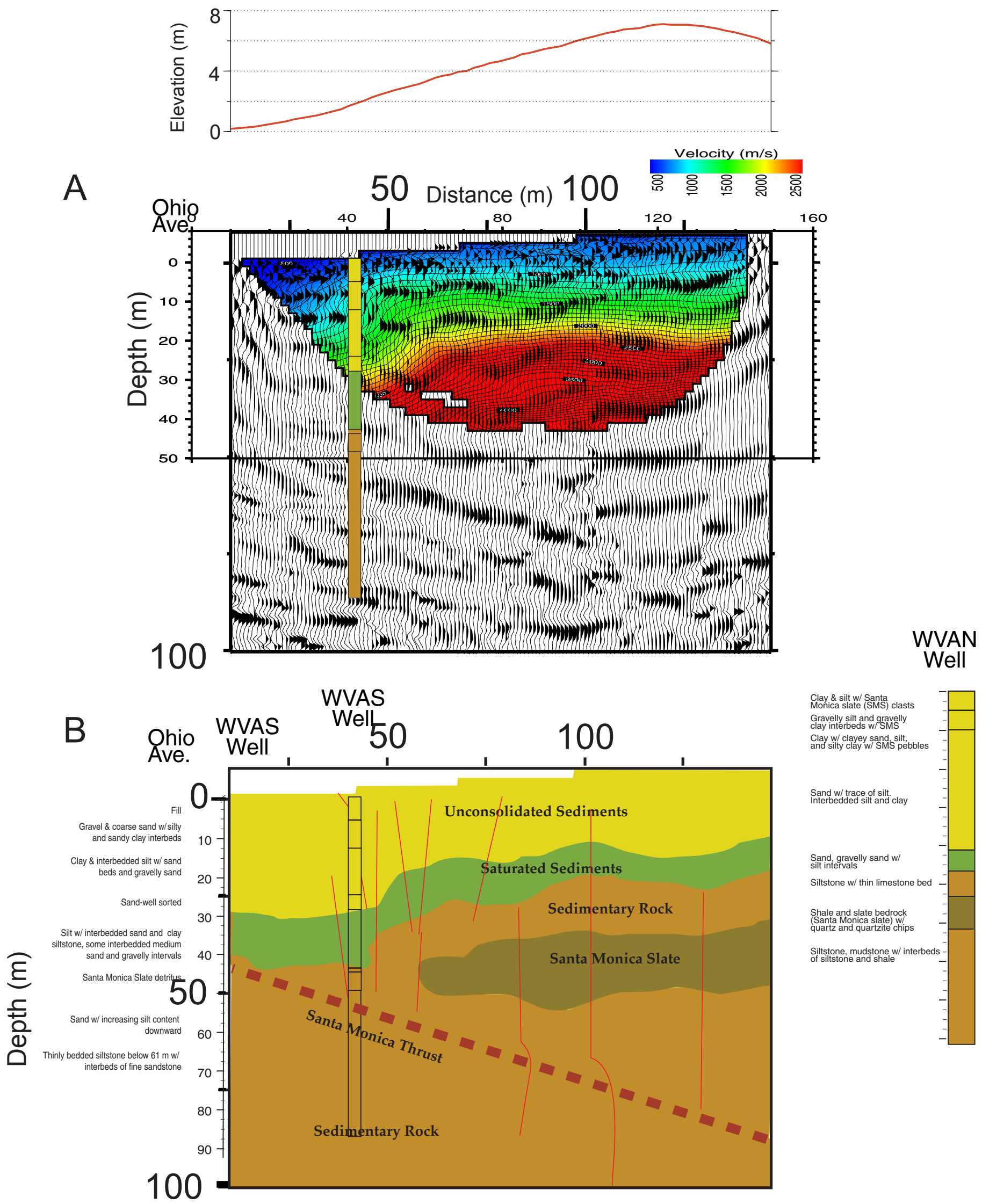

Fig. 10 (a) Seismic reflection image of the upper $100 \mathrm{~m}$ along the WVAH profile with the seismic velocity inversion model superimposed. (b) Interpretative geologic model along the WVAH seismic profile based on seismic reflection images, seismic refraction velocities, and well logs. Well logs from Gibbs et al.(2000). The WVAS and WVAN wells are located $\sim 250 \mathrm{~m}$ northeast and $\sim 600 \mathrm{~m}$ northwest, respectively, of the profile. 


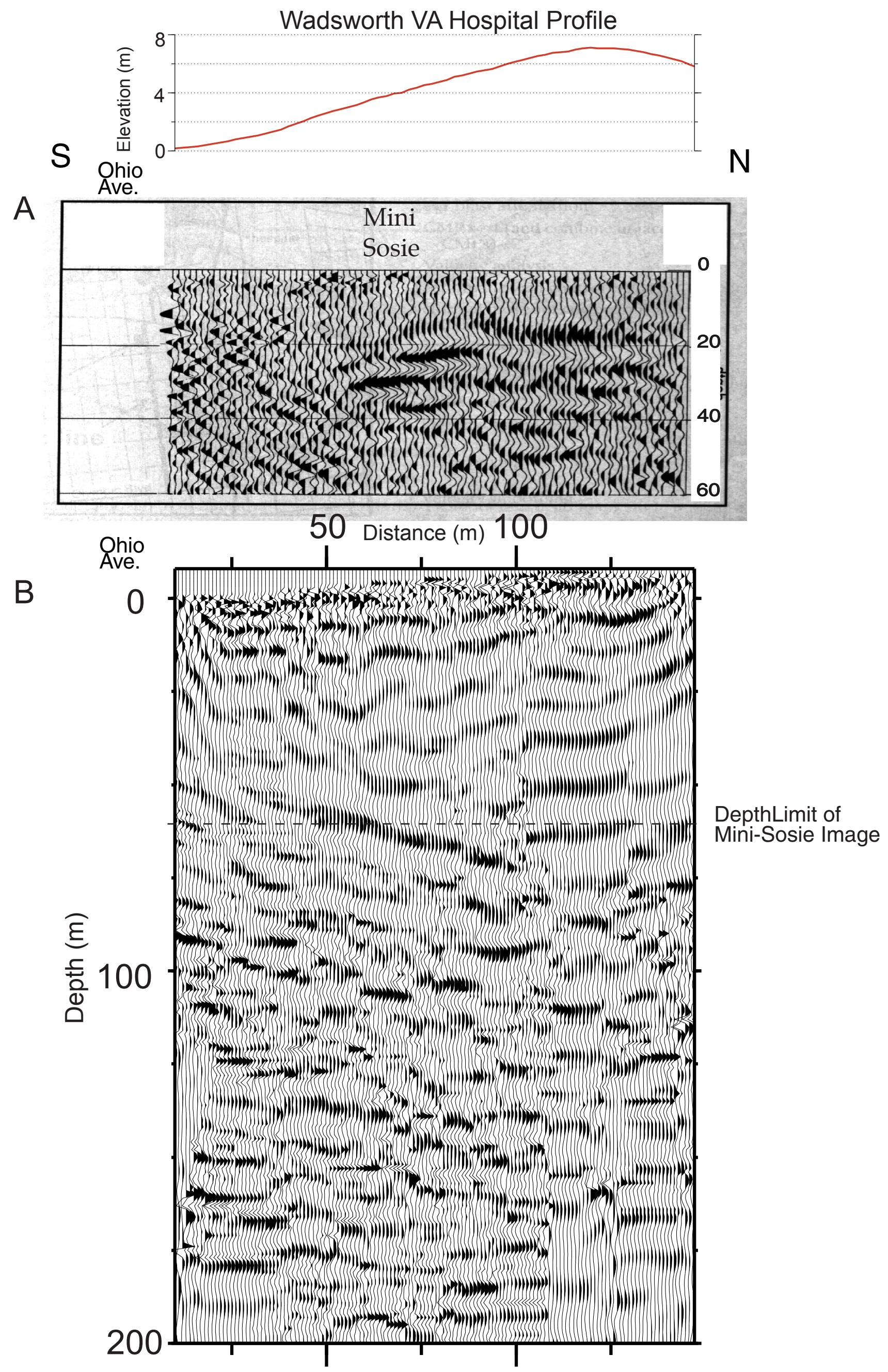

Fig. 11 (a) Mini-sosie seismic reflection profile recorded along the WVAH profile. (b) Seismic profile from this study. 


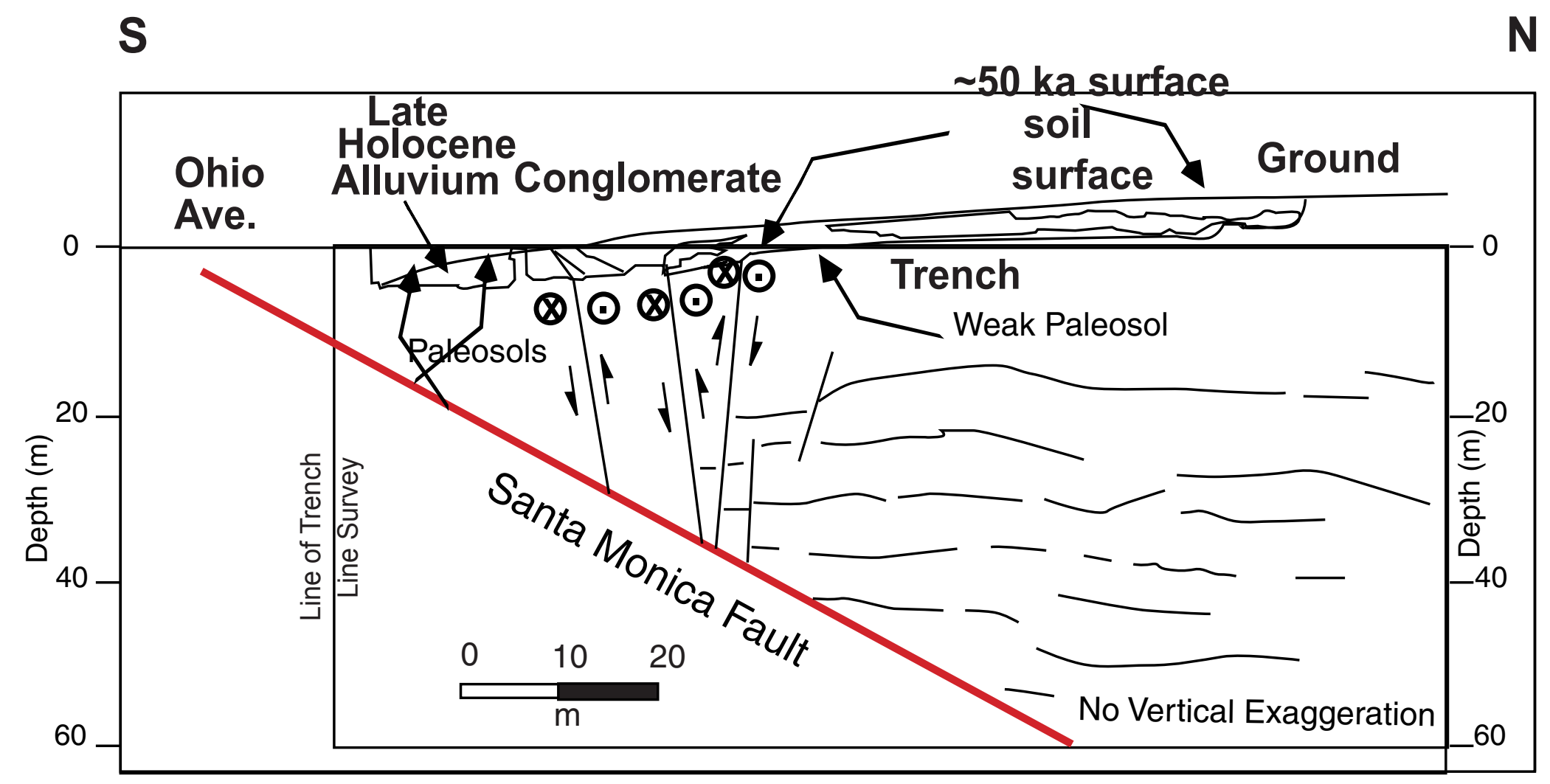

Fig 12. Geologic interpretative line drawing based on results from trenching and previous seismic imaging (from Dolan et al., 1997). 

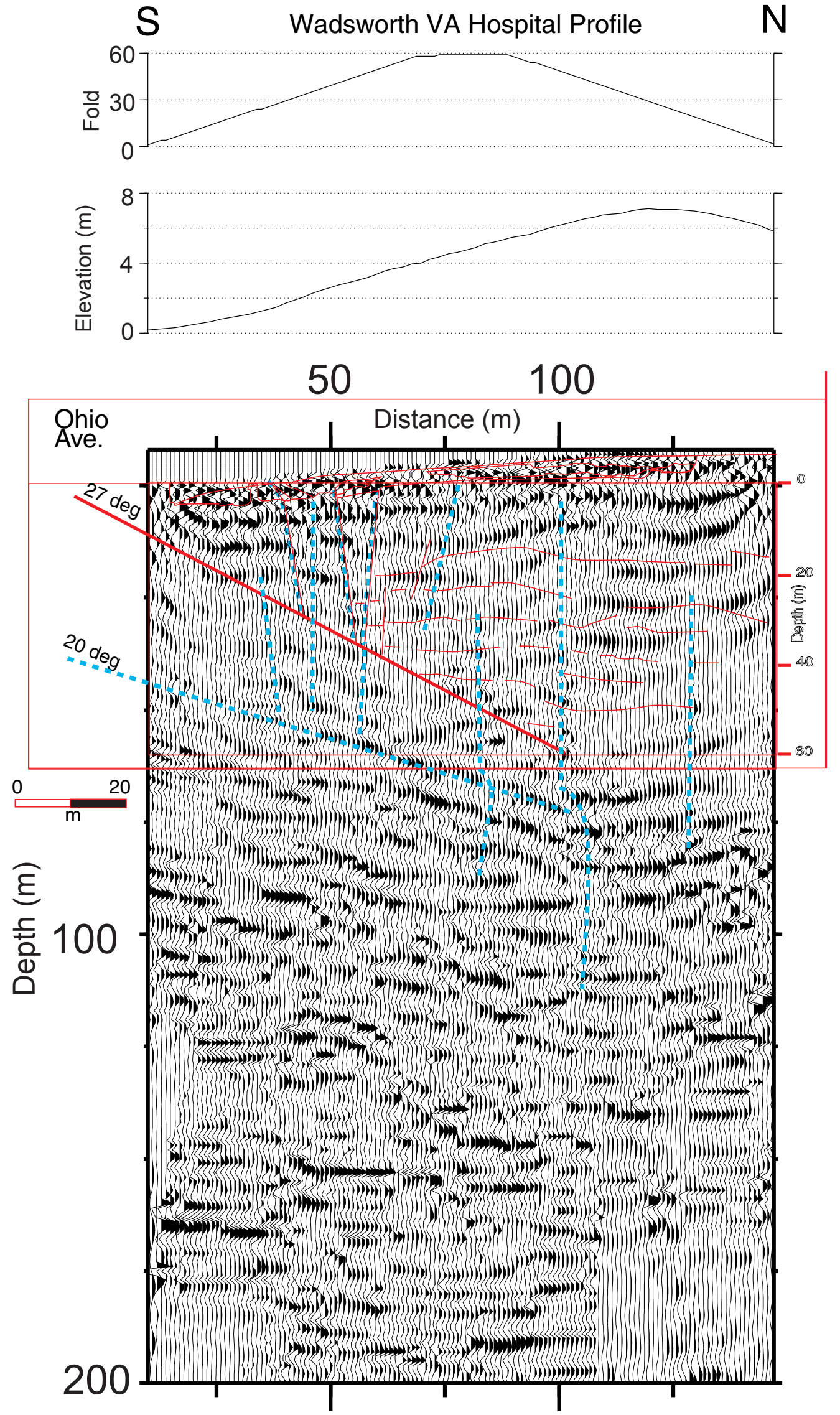

Fig. 13a WVAH seismic image with geologic model of Dolan et al. (1997) superimposed (in red). Blue lines show interpreted structure from this study. 

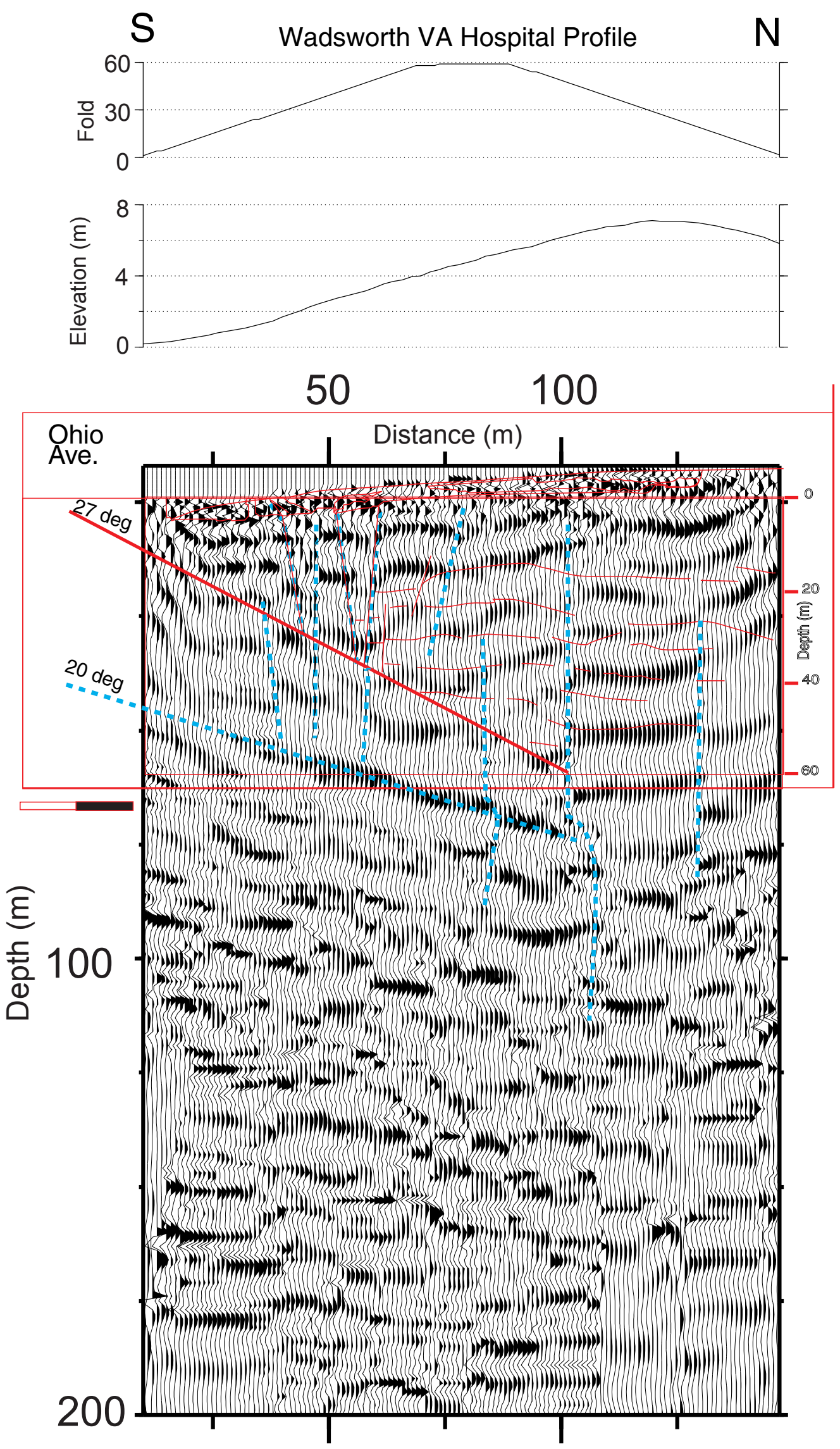

Fig. 13b WVAH seismic image (low freq) with geologic model of Dolan et al. (1997) superimposed (in red). Blue lines show interpreted structure from this study. 
Time (s)

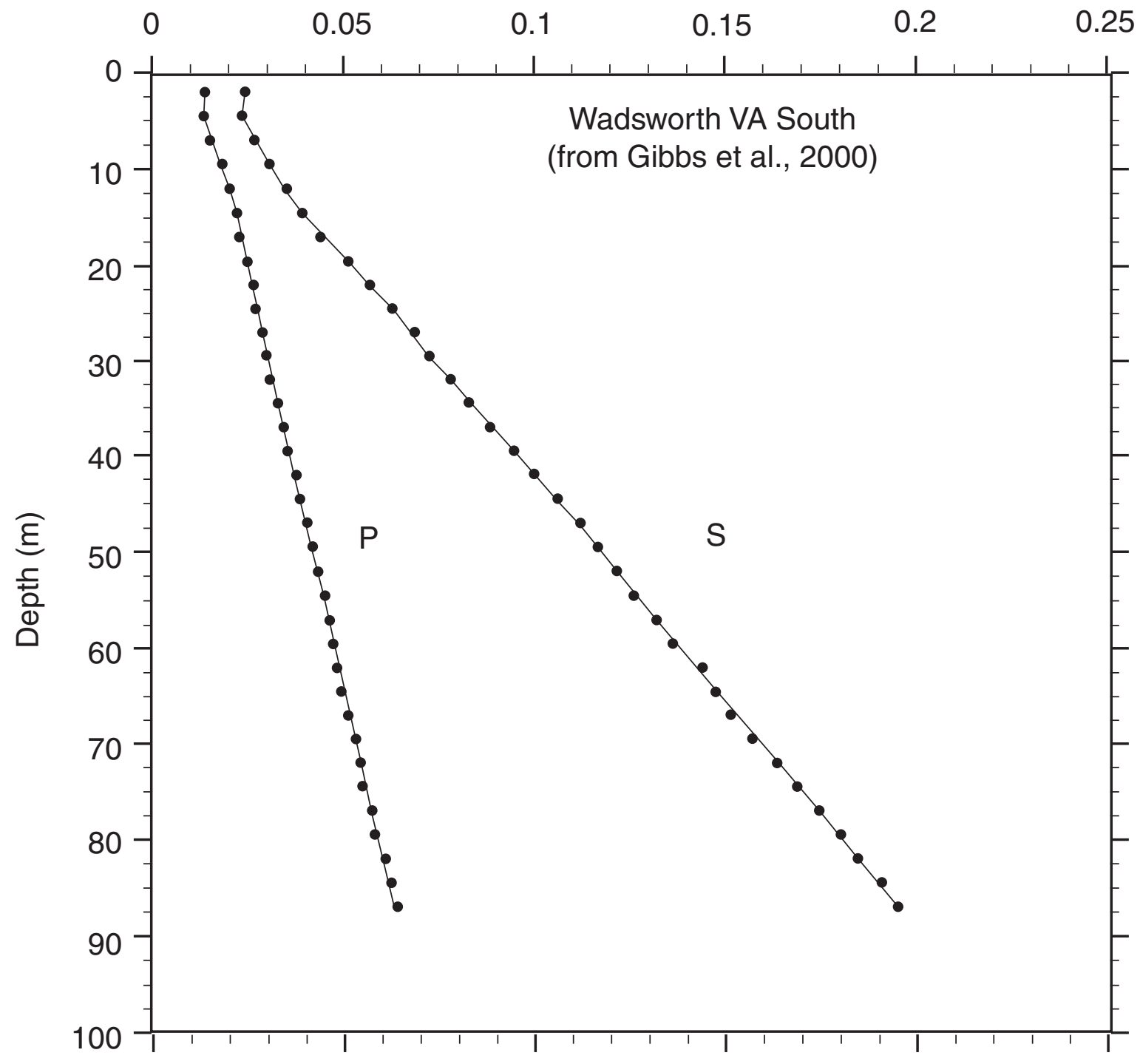

Fig. 14a First-arrival picks from borehole velocity measurements of Gibbs et al. (2000). 


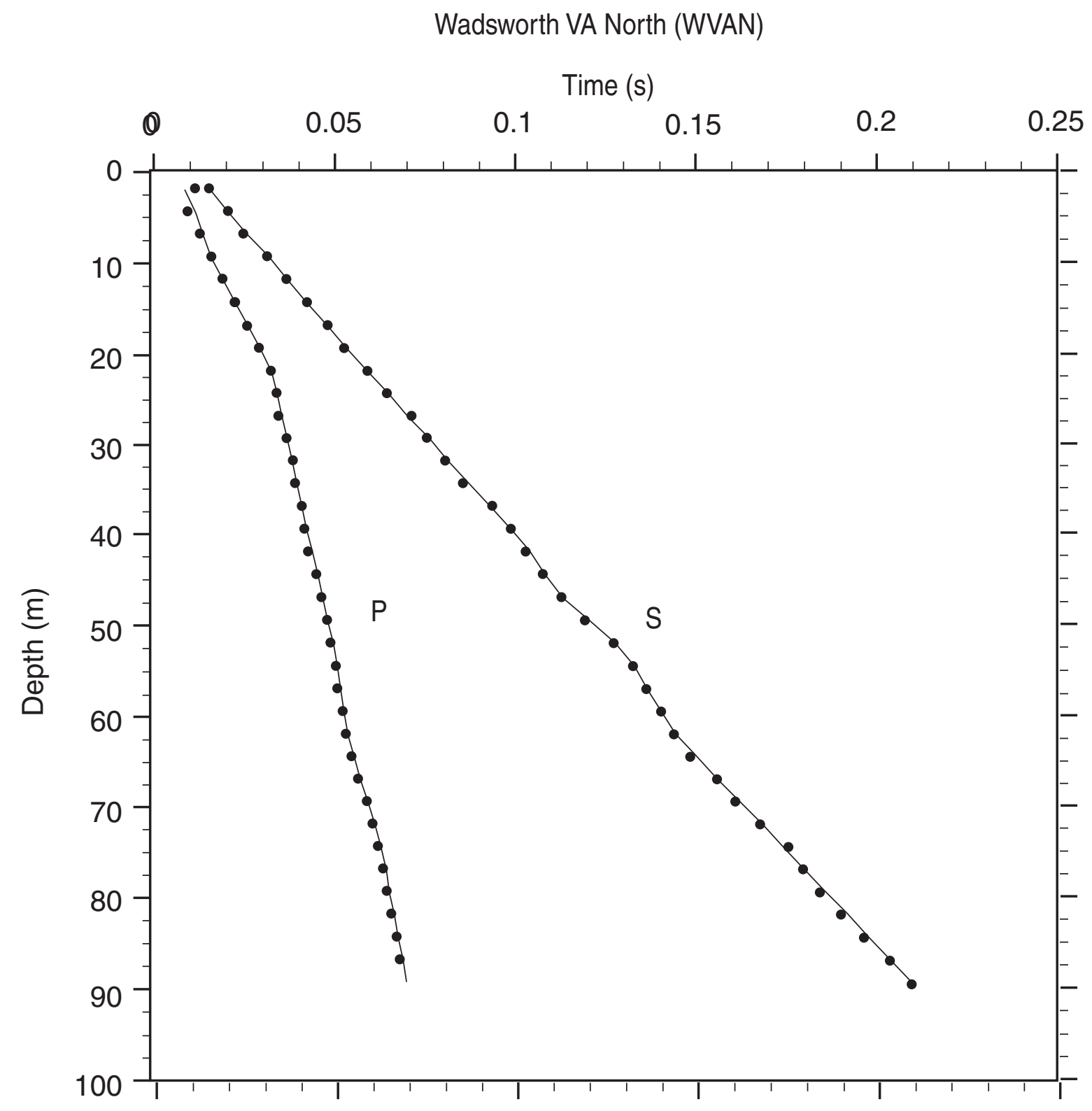

Fig. 14b First-arrival travel time picks for downhole seismic data acquired at the Wadsworth VA Hospital, northern well (from Gibbs et al., 2000) 


\section{Wadsworth VA Hospital - South (WVAS)}

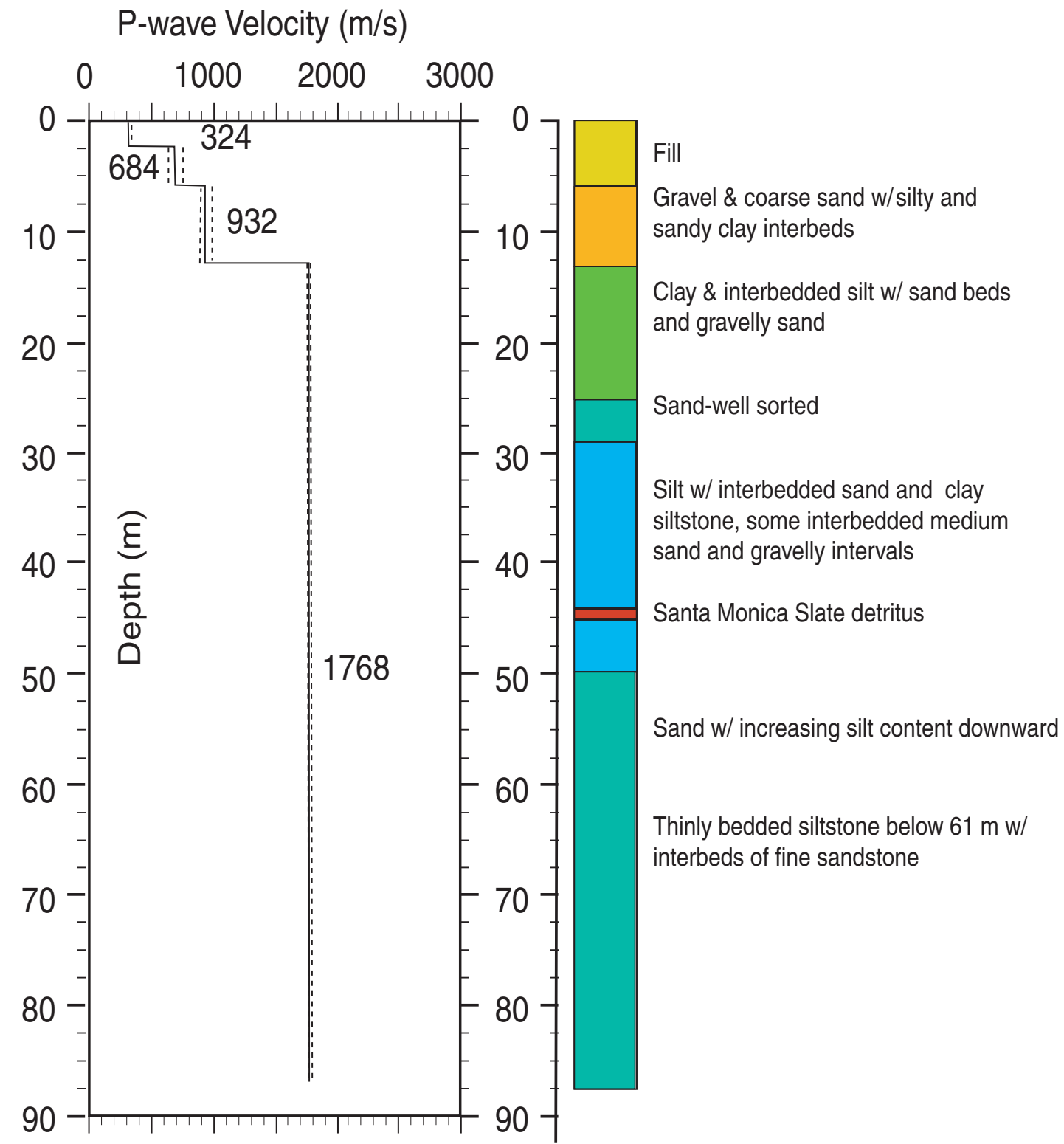

Fig. 15a Seismic compressional-wave velocity profile and well log for the Wadsworth VA Hospital southern well (from Gibbs et al., 2000). Velocities are determined by least-square fits to data shown in figure 14a. Dashed lines depict plus or minus one standard deviation. 
Wadsworth VA North (WVAN)

P-Wave Velocity $(\mathrm{m} / \mathrm{s})$

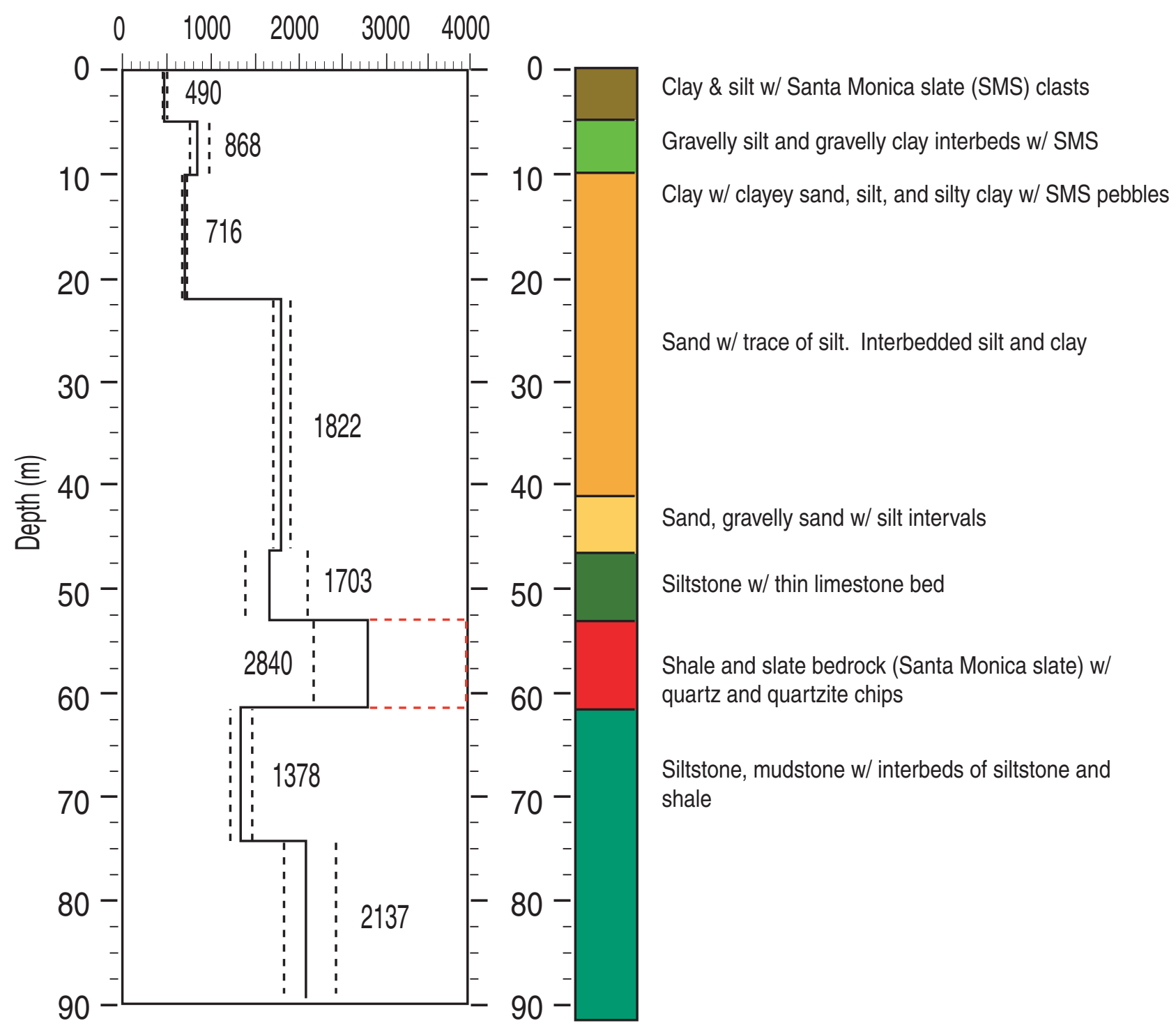

Fig. 15b Seismic compressional-wave velocity model for Wadsworth VA North well. The dashed lines represent plus and minus one standard deviation of velocity measurements. The generalized geologic well log is shown to the right. From Gibbs et al. (2000). Note that velocities as high as $4000 \mathrm{~m} / \mathrm{s}$ are possible at depths between 50 and $60 \mathrm{~m}$. 